\title{
PREDICTING SCALAR SOURCE-SINK AND FLUX DISTRIBUTIONS WITHIN A FOREST CANOPY USING A 2-D LAGRANGIAN STOCHASTIC DISPERSION MODEL
}

\author{
CHENG-I HSIEH $^{1, \star}$, MARIO SIQUEIRA ${ }^{2}$, GABRIEL KATUL $^{2}$ and CHIA-REN CHU ${ }^{3}$ \\ ${ }^{1}$ Department of Bioenvironmental Systems Engineering, National Taiwan University, Taipei 10673, \\ Taiwan; ${ }^{2}$ School of the Environment, Duke University, Durham, NC 27708, U.S.A.; ${ }^{3}$ Department of \\ Civil Engineering, National Central University, Chun-Li 32054, Taiwan
}

(Received in final form 1 December 2002)

\begin{abstract}
This study proposes a two-dimensional Lagrangian stochastic dispersion model for estimating spatial and temporal variation of scalar sources, sinks, and fluxes within a forest canopy. Carbon dioxide and heat dispersion experiments were conducted for field testing the model. These experiments also provided data for field testing a newly developed one-dimensional Lagrangian analytical dispersion model. It was found that these two models produce similar scalar source-sink and flux distribution patterns. Comparing with $\mathrm{CO}_{2}$ flux measurements, the one-dimensional model performed as well as the two-dimensional model even when the fetch is short $(\approx 100 \mathrm{~m})$. To drive these Lagrangian models, velocity statistics through the canopy volume must be specified a priori. The sensitivity of the computed sources, sinks, and fluxes to the description of the flow statistics was further examined. All in all, we found good agreement between model predicted and eddy-correlation measured $\mathrm{CO}_{2}$ and sensible heat fluxes.
\end{abstract}

Keywords: Biosphere-atmosphere exchange, Canopy turbulence, $\mathrm{CO}_{2}$ flux, Inverse model, Lagrangian model, Scalar source-sink.

\section{Introduction}

Estimating concentrations, sources, sinks, and fluxes of heat, water vapour, $\mathrm{CO}_{2}$, and other scalar entities (e.g., $\mathrm{CH}_{4}$ ) within and above vegetation canopies continues to be an active research problem in micrometeorology (Katul et al., 1997, 2001; Warland and Thurtell, 2000; Siqueira et al., 2000; Leuning, 2000). Establishing the relationship between source strength and concentration profiles is essential for such problems and provides practical methodology for long-term field studies currently underway (Kaiser, 1998; Falge et al., 2001a, b). As discussed in Raupach (1989a, b), it is helpful to distinguish between two classes of problems: the 'forward problem' of predicting the concentration field emanated from a given source, and the 'inverse problem' of inferring the source-sink profile from concentration measurements. This study focuses on the latter problem for $\mathrm{CO}_{2}$ and heat within a forest canopy.

^ E-mail: hsieh@ntu.edu.tw 
Raupach (1989a, b) developed the 'Localized Near Field (LNF)' theory, which separates the dispersion process into near-field (non-diffusive) and far-field (diffusive) and provides a quasi-analytical Lagrangian solution for linking source strength and its resulting concentration profile. The LNF theory has been widely adopted for inferring scalar sources and fluxes though its performance was found to be between fair and good (Denmead, 1995; Katul et al., 1997, 2001; Leuning et al., 2000). To alleviate some of the theoretical limitations imposed by LNF, Katul and Albertson (1999) proposed an Eulerian approach to infer scalar fluxes using simplifications to a turbulent flux budget equation in conjunction with concentration measurements and velocity statistic profiles calculated by a second-order closure model (Wilson and Shaw, 1977). Siqueira et al. (2000) compared the performance of this Eulerian approach with LNF theory modified to include a smoothness constrain and a hybrid Eulerian-Lagrangian model. Though the fundamentals of these three methods are very different, they concluded that all the models gave comparable predictions of scalar source-sink and flux profiles and recommended that these models be used in concert with each other.

Recently, based on Taylor's (1921) dispersion theory and Gaussian homogeneous turbulence assumption, Warland and Thurtell (2000) developed an analytical Lagrangian model to represent the dispersion process continuously from near-field to far-field and relate the source density to the gradients in concentration. Using the Coppin et al. (1986) wind-tunnel heat dispersion experiment, they demonstrated that their model captured the near-field effect better than LNF. However, in-situ experiments are still required for testing this model.

When applying any of the above mentioned models to infer scalar sources and sinks, two important factors must be considered. First, these models are onedimensional and neglect advective transport by the mean wind. Hence, it might be inappropriate to adopt these models to conditions where advection is significant. Second, in order to drive these models, it is necessary to specify (or calculate) the flow field a priori. The flow field can be estimated from higher-order closure models (Ayotte et al., 1999; Massman and Weil, 1999; Katul and Albertson, 1998; Katul and Chang, 1999) or by canonical velocity statistic profiles derived from comparable field experiments (Raupach et al., 1996). These estimated profiles represent ensemble-averaged (average over many sampling runs) flow properties that do not explicitly resolve individual run-by-run variation partly induced by changes in local atmospheric stability. While some studies considered the effects of atmospheric stability through its role on the upper boundary condition (Leuning, 2000), local stability effects on the flow statistics inside the canopy are commonly averaged out. Whether incorporating the run-by-run variation in flow statistics improves the source and flux estimations is not well explored.

The objective of this study is to investigate a two-dimensional Lagrangian stochastic dispersion model for estimating scalar source-sink and flux distributions and to examine the two limiting factors described above. Dispersion experiments for $\mathrm{CO}_{2}$ and sensible heat were conducted at Duke Forest for testing the proposed 
model. Comparisons between this two-dimensional model and the newly proposed one-dimensional Lagrangian analytical model of Warland and Thurtell (2000) are also presented.

\section{Theory and Methods}

\subsection{LAGRANGIAN STOCHASTIC DISPERSION MODEL}

In the Lagrangian frame of reference, the scalar source density $S(x, y, z, t)$ and concentration $C(x, y, z, t)$ are related by

$$
\begin{aligned}
C(x, y, z, t)= & \int_{-\infty}^{t} \int_{0}^{\infty} \int_{-\infty}^{\infty} \int_{-\infty}^{\infty} S\left(x_{0}, y_{0}, z_{0}, t_{0}\right) \\
& \times P\left(x, y, z, t \mid x_{0}, y_{0}, z_{0}, t_{0}\right) \mathrm{d} y_{0} \mathrm{~d} x_{0} \mathrm{~d} z_{0} \mathrm{~d} t_{0},
\end{aligned}
$$

where $P\left(x, y, z, t \mid x_{0}, y_{0}, z_{0}, t_{0}\right)$, the transition probability density function, describes the probability density of a tracer particle found at $(x, y, z, t)$ and which was originally released at $\left(x_{0}, y_{0}, z_{0}, t_{0}\right)$, where $x, y, z, t$ denote the longitudinal, lateral, vertical, and time axes, respectively. Considering a limited homogeneous streamwise and uniformly infinite cross-streamwise source density distribution under steady state condition, (1) can be simplified to a two-dimensional form as

$$
C(x, z)=\int_{-\infty}^{\infty} \int_{0}^{\infty} \int_{-\infty}^{t} S\left(z_{0}\right) P\left(x, z, t \mid x_{0}, z_{0}, t_{0}\right) \mathrm{d} t_{0} \mathrm{~d} z_{0} \mathrm{~d} x_{0} .
$$

If $P$ is known, then (2) can be used to solve the forward and inverse problems (Raupach, 1989a). In the one-dimensional case, $P$ can be readily estimated by LNF theory. Here, $P$ is two-dimensional and can be calculated by the Lagrangian stochastic dispersion model of particle trajectory simulations. The Lagrangian stochastic model is based on the assumption that the evolution of the position $\left(x_{i}\right)$ and velocity $\left(u_{i}\right)$ of a fluid element is a Markov process. Basic concepts, details, and many references are summarized in Rodean (1996). Following this assumption, the stochastic equations describing the particle velocity and position are

$$
\begin{aligned}
& \mathrm{d} u_{i}=a_{i}\left(x_{i}, u_{i}, t\right) \mathrm{d} t+b_{i j}\left(x_{i}, u_{i}, t\right) \mathrm{d} \lambda_{j}, \\
& u_{i}(t)=u_{i}\left(t_{0}\right)+\int_{t_{0}}^{t} \mathrm{~d} u_{i}
\end{aligned}
$$

and

$$
\mathrm{d} x_{i}=u_{i} \mathrm{~d} t
$$




$$
x_{i}(t)=x_{i}\left(t_{0}\right)+\int_{t_{0}}^{t} \mathrm{~d} x_{i}
$$

where the sub-indexes $i$ and $j=1,2$, or 3 with summation implied over repeated indexes, and $x_{1}=x, x_{2}=y, x_{3}=z$, and $u_{1}=u, u_{2}=v, u_{3}=w$ are the longitudinal, lateral, and vertical velocities, respectively (since this study considers a two-dimensional frame, $i$ and $j=1$ and 3 only). In (3), $a_{i}$ can be interpreted as a drift coefficient vector, $b_{i j}$ is the random acceleration tensor, $\mathrm{d} t$ is the time interval, and $\mathrm{d} \lambda$ is a Gaussian random increment with zero mean and variance $\mathrm{d} t$. Once coefficients $a$ and $b$ are determined, then the formulation for particle trajectories is established. So far, the most rigorous criterion for determining $a$ is Thomson's (1987) well-mixed condition while $b$ can be determined by Kolmogorov's theory for the inertial subrange. The well-mixed condition states that if the tracer particles are initially uniformly distributed (well-mixed), they should remain so during the dispersion process. Unfortunately, the well-mixed condition is not sufficient for selecting a unique solution for the coefficient $a$ in more than one-dimensional flows. Efforts have been made to provide a criterion for distinguishing better Lagrangian stochastic formulations within the 'well-mixed' family (e.g., Reynolds 1998a, b; Borgas et al., 1997; Wilson and Flesch, 1997), but not enough improvement over Thomson's (1987) model was achieved (Sawford, 1999; Kurbanmuradov and Sabelfeld, 2000). In this study, assuming steady state, Thomson's solution was adopted in which coefficients $a$ and $b$ were given by

$$
\begin{aligned}
a_{i}=- & b_{i k} b_{j k}\left(V^{-1}\right)_{j k}\left(u_{k}-U_{k}\right)+\frac{\phi_{i}}{g_{a}}, \\
\frac{\phi_{i}}{g_{a}}= & \frac{1}{2} \frac{\partial V_{i l}}{\partial x_{l}}+\frac{\partial U_{i}}{\partial t}+U_{l} \frac{\partial U_{i}}{\partial x_{l}} \\
& +\left(\frac{1}{2}\left(V^{-1}\right)_{l j}\left(\frac{\partial V_{i l}}{\partial t}+U_{m} \frac{\partial V_{i l}}{\partial x_{m}}\right)+\frac{\partial U_{i}}{\partial x_{j}}\right)\left(u_{j}-U_{j}\right) \\
& +\frac{1}{2}\left(V^{-1}\right)_{l j} \frac{\partial V_{i l}}{\partial x_{k}}\left(u_{j}-U_{j}\right)\left(u_{k}-U_{k}\right), \\
b_{i j}= & \delta_{i j}\left(C_{0} \epsilon\right)^{1 / 2} \approx \delta_{i j}\left(\frac{2 \sigma_{w}^{2}}{t_{L}}\right)^{1 / 2} .
\end{aligned}
$$

In (5a), (5b), and (6), the sub-indices $i$ and $j=1,2$, and 3 with summation over the repeated index, $U_{i}$ is the mean Eulerian velocity, the tensor $V_{i j}$ is defined as $V_{i j}=\overline{\left(u_{i}-U_{i}\right)\left(u_{j}-U_{j}\right)}$, the overbar denotes an ensemble average, $\sigma_{w}^{2}$, the vertical velocity variance, is the one-dimensional form of $V_{i j}, C_{0}$ is the Kolmogorov constant and $\epsilon$ is the mean turbulent kinetic energy dissipation rate, and the quantity $C_{0} \epsilon$ is approximated by $2 \sigma_{w}^{2} / t_{L}$, where $t_{L}$ is the Lagrangian decorrelation time 
scale. Note that non-Gaussian turbulence is not considered in (5a) and (6). It was demonstrated that models that include non-Gaussian turbulence do not outperform those with a Gaussian turbulence assumption (Wilson and Sawford, 1996).

By releasing an ensemble of particles and using (3) to (6), we calculate the trajectories of particles and the transition probability density function, $P\left(x_{i}, t \mid x_{i o}, t_{o}\right)$. In conjunction with (2), the concentration $C\left(x_{i}, t\right)$ can then be calculated when a source strength is specified. Notice that coefficients $a$ and $b$ are functions of the Eulerian velocity statistics (i.e., $U_{i}$ and $V_{i j}$ ) and Lagrangian time scale. Hence for driving the Lagrangian stochastic model, flow statistics need to be specified a priori. In this study, the flow statistics were determined from direct field measurements.

\subsection{CONSTRUCTING THE INTEGRATED PROBABILITY DENSITY FUNCTION (PDF) MATRIX}

From a given scalar concentration profile and $P$ calculated from the Lagrangian model, (2) can be used for estimating scalar source and sink strength (the inverse problem). In practice, scalar concentrations are not continuously measured within the canopy space but in discrete layers, thus this inverse problem must be solved discretely and an integrated probability density function (PDF) matrix is constructed. Suppose the canopy source is divided into m layers (source from the ground is included in the lowest layer) and each layer has a uniform source density, $S_{j}$, over its depth, $\Delta z_{j}$, where $j=1, \ldots, m$. Also, suppose the concentration measurement, $C_{i}$, is available in n layers, where $i=1, \ldots, n$. The integrated PDF matrix, $M_{i j}$ is defined as the concentration at the $i$ th concentration-layer produced by placing a unit source strength at the $j$ th source-layer through the whole horizontal $(x)$ source domain. Since the source strength is unity, the concentration is the integration of the transition probability density function over $x$ and time. Mathematically, $M_{i j}$, is defined as

$$
M_{i j}=\int_{-\infty}^{\infty} \int_{-\infty}^{t} P\left(x, z_{i}, t \mid x_{0}, z_{j}, t_{0}\right) \mathrm{d} t_{0} \mathrm{~d} x_{0} .
$$

Once $M_{i j}$ is known, the source profile can be solved by

$$
C_{i}=\sum_{j=1}^{m} M_{i j} S_{j} \Delta z_{j},
$$

which is the discrete form of (2). Notice that in a one-dimensional Lagrangian frame of reference, $M_{i j}$ is readily obtained by integrating over the time domain only, and is termed as the dispersion matrix in Raupach (1989b). However, the measured concentration, $C_{i}$, may not only result from the scalar sources and sinks within the canopy. Hence a background scalar concentration must be deduced as 
well. Generally, the background concentration need not be readily available or conveniently defined. For carbon dioxide, the measured concentration above the forest canopy might be treated as a reasonable background concentration. However, this is not the case for temperature under non-neutral conditions. To overcome this problem, we set a reference layer (in theory, it can be any layer, but in practice, it is better to set the reference layer between the highest and lowest measured concentration-layer) and (7) is revised to

$$
C_{i}-C_{r}=\sum_{j=1}^{m}\left(M_{i j}-M_{r j}\right) S_{j} \Delta z_{j},
$$

where subscript $r$ denotes the reference layer. If $n=m+1$, then (8) will provide a unique solution for $m$ layers of source-sink profile (since one layer is used for reference and contains no additional information). If $n>m+1$, then (8) can also be conveniently solved by the singular value decomposition (SVD) technique (Press et al., 1992). Let $\mathbf{M}$ denote the $n \times m$ integrated PDF matrix, $M_{i j}-M_{r j}$, $\mathbf{C}$ denote the vector, $C_{i}-C_{r}$, and $\mathbf{S}$ denote the vector, $S j \Delta z j$, where $j=1,2, \ldots, m$, $i=1,2, \ldots, n+1$, and the $(n+1)$ th layer is the reference layer. The solution for $\mathbf{S}$ by SVD is

$$
\mathbf{S}=\mathbf{R} \cdot \mathbf{Q} \cdot \mathbf{D}^{T} \cdot \mathbf{C},
$$

where $\mathbf{D}$ is an $n \times m$ column orthogonal matrix, $\mathbf{Q}$ is an $m \times m$ diagonal matrix with positive or zero elements (i.e., the singular values), $\mathbf{R}$ is an $m \times m$ column orthogonal matrix, and $M=\mathbf{D} \cdot \mathbf{Q} \cdot \mathbf{R}^{T}$. Another method to solve (8) when $n>$ $m+1$ is the least-squares solution by Raupach (1989b), where $\mathbf{S}$ is determined by solving the following $m$ linear equations for $S_{k}$,

$$
\begin{aligned}
& \sum_{k=1}^{m} A_{j k} S_{k}=B_{j}, \\
& A_{j k}=\sum_{i=1}^{n}\left(M_{i j}-M_{r j}\right) \Delta z_{j}\left(M_{i k}-M_{r k}\right) \Delta z_{k}, \\
& B_{j}=\sum_{i=1}^{n}\left(C_{i}-C_{r}\right)\left(M_{i j}-M_{r j}\right) \Delta z_{j} .
\end{aligned}
$$

Once the source strength is computed, the scalar flux $F(x, z)$ can be determined by

$$
F(x, z)=\overline{w(x, z) C(x, z)},
$$


where $C(x, z)$ is calculated by (2) using the source strength distribution solved by (8), and $w$ is a Lagrangian velocity at $(x, z)$. For one-dimensional stationary flows or cases where advection by the mean wind is negligible, $F$ can be calculated from

$$
F(z)=F(0)+\int_{0}^{z} S(z) \mathrm{d} z .
$$

\subsection{WARLAND AND ThURTELl (2000) MODEL}

Following Taylor's (1912) dispersion theory and assuming steady Gaussian homogeneous turbulence, Warland and Thurtell (2000) recently proposed a onedimensional integrated PDF matrix, $N_{i j}$, to link concentration gradient and source strength as

$$
\frac{\mathrm{d} C_{i}}{\mathrm{~d} z_{i}}=\sum_{j=1}^{m} N_{i j} S_{j} \Delta z_{j}
$$

where $i$ and $j$ are concentration- and source-layer indices, respectively, as discussed in Section 2.2. Warland and Thurtell's model is analytical and the advantage of using it to solve the inverse problem is that a reference layer is not necessary. In (14), $N_{i j}$ is a function of the Lagrangian turbulent dispersion and is calculated as

$$
\begin{aligned}
N_{i j}= & \frac{-\left(1-\exp \left(\left(-\left(\left(z_{i}-z_{j}\right)^{2}\right) /\left(2 \Delta z_{j}^{2}\right)\right)\right)\right.}{2 \sigma_{w i} L_{i}\left(1-\exp \left(-(\pi / 2)^{1 / 2}\left(z_{i}-z_{j}\right) /\left(\left(L_{i}+L_{j}\right) / 2\right)\right)\right)} \\
& -\frac{\left(1-\exp \left(\left(-\left(z_{i}+z_{j}\right)^{2}\right) /\left(2 \Delta z_{j}^{2}\right)\right)\right)}{2 \sigma_{w i} L_{i}\left(1-\exp \left(-(\pi / 2)^{1 / 2}\left(z_{i}+z_{j}\right) /\left(\left(L_{i}+L_{j}\right) / 2\right)\right)\right)}
\end{aligned}
$$

for $z_{i}>z_{j}$,

$$
N_{i j}=\frac{-\left(1-\exp \left(\left(-\left(z_{i}+z_{j}\right)^{2}\right) /\left(2 \Delta z_{j}^{2}\right)\right)\right)}{2 \sigma_{w i} L_{i}\left(1-\exp \left(-(\pi / 2)^{1 / 2}\left(z_{i}+z_{j}\right) /\left(\left(L_{i}+L_{j}\right) / 2\right)\right)\right)}
$$

for $z_{i}=z_{j}$, and

$$
\begin{aligned}
N_{i j}= & \frac{-\left(1-\exp \left(\left(-\left(\left(z_{i}-z_{j}\right)^{2}\right) /\left(2 \Delta z_{j}^{2}\right)\right)\right)\right.}{2 \sigma_{w i} L_{i}\left(1-\exp \left(-(\pi / 2)^{1 / 2}\left(z_{j}-z_{i}\right) /\left(\left(L_{i}+L_{j}\right) / 2\right)\right)\right)} \\
& -\frac{\left(1-\exp \left(\left(-\left(z_{i}+z_{j}\right)^{2}\right) /\left(2 \Delta z_{j}^{2}\right)\right)\right)}{2 \sigma_{w i} L_{i}\left(1-\exp \left(-(\pi / 2)^{1 / 2}\left(z_{i}+z_{j}\right) /\left(\left(L_{i}+L_{j}\right) / 2\right)\right)\right)}
\end{aligned}
$$

for $z_{i}<z_{j}$. In (15), $L$ is a Lagrangian length scale defined as $\sigma_{w} t_{L}$. If profiles of $t_{L}$ and $\sigma_{w}$ are known, then (14) in conjunction with (15) can be used to 
solve both the forward and inverse problems. Strictly speaking, the $\sigma_{w i}$ should be a constant $\sigma_{w}$ and the $L_{i}$ and $L_{j}$ should be equal to the homogeneous $L$. Warland and Thurtell adapt their model to inhomogeneous turbulence by choosing $\sigma_{w i}$ at the field point $z_{i}$ and $L$ to be the average of $L_{i}$ and $L_{j}$. Since canopy turbulence is highly inhomogeneous, the success of this model depends on whether we can apply a homogeneous solution to inhomogeneous flows. Field tests conducted on the LNF (Denmead, 1995; Leuning et al., 2000; Siqueira et al., 2000) suggest that such an approximation is valid (LNF is also derived under the same assumption).

\section{Experiments}

The experimental site is located at the Blackwood division of Duke Forest, near Durham, North Carolina $\left(35^{\circ} 98^{\prime} \mathrm{N}, 79^{\circ} 8^{\prime} \mathrm{W}\right.$, elevation $\left.=163 \mathrm{~m}\right)$. The site is a uniform-age managed loblolly pine forest that extends $1 \mathrm{~km}$ in the north-south direction and $0.6 \mathrm{~km}$ in the east-west direction and is surrounded by hardwood forests on east and west sides. The tree stands are originally grown from seedlings planted at $2.4 \mathrm{~m}$ by $2.4 \mathrm{~m}$ spacing in 1983 following clear cutting and burning. A typical leaf area density profile, normalized by the canopy height $(h)$, is shown in Figure 1a, where three peaks are evident and the maximum leaf area density occurs at $6.5 \mathrm{~m}$ from the forest floor. Total leaf area index for the stand was $3.1 \mathrm{~m}^{2} \mathrm{~m}^{-2}$ at the time of the experiments. Topographic variations within the stand are small (terrain slope changes $<5 \%$ ). This site is equipped with seven walkup towers, which are parts of the on-going Forest-Atmosphere Carbon Transfer (FACTS) experiment. Further details about the site can be found in Ellsworth et al. (1995).

Carbon dioxide and heat dispersion experiments were carried out to examine the model performance in predicting scalar source-sink and flux. Velocity statistics were also measured for driving the two Lagrangian models.

\section{1. $\mathrm{CO}_{2}$ DISPERSION EXPERIMENT}

This $\mathrm{CO}_{2}$ dispersion experiment was conducted at the prototype walkup tower of the FACTS project. To characterize the turbulent structure of the canopy flow at this site, five Campbell Scientific sonic anemometers (CSAT3) were installed at heights of 4.2, 6.0, 9.7, 13.0, and $16.0 \mathrm{~m}$, respectively, on the tower to measure the three velocity components $(u, v$, and $w$ ) between May 25 and June 11, 1997. The mean canopy height was $13 \mathrm{~m}$. The sampling frequency was $10 \mathrm{~Hz}$ and sampling period was $30 \mathrm{~min}$. Figures $1 \mathrm{~b}-\mathrm{f}$ show the normalized profiles of mean wind speed, $U / U_{h}$ ( $U_{h}$ is $U$ measured at the canopy top), Reynolds stress, $-\left\langle u^{\prime} w^{\prime}\right\rangle / u_{*}^{2}\left(u^{\prime}\right.$ and $w^{\prime}$ are the fluctuations of $u$ and $w$ from the mean, \langle\rangle denotes time average, and $u_{*}$ is friction velocity at the canopy top), horizontal velocity variance, $\sigma_{u} / u_{*}$, vertical velocity variance, $\sigma_{w} / u_{*}$, and Lagrangian time scale, $t_{L} u_{*} / h$ (here $t_{L}$ is a parameterization), as a function of normalized height, $z / h$, respectively. In Figure 

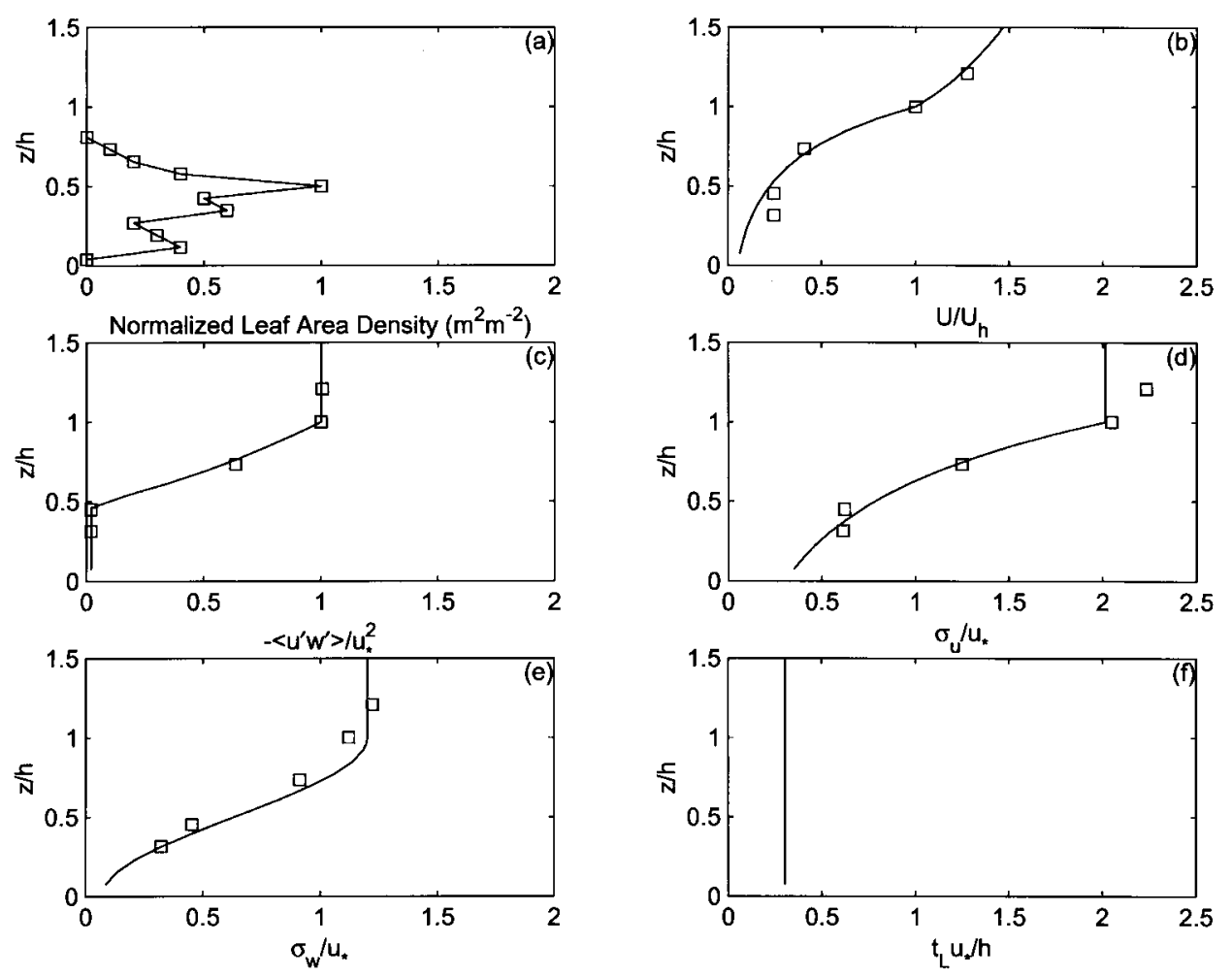

Figure 1. (a) The measured leaf area density, normalized by the canopy height $(h)$, in units of $\mathrm{m}^{2}$ $\mathrm{m}^{-2}$, as a function of normalized height $(z / h)$. (b) Mean horizontal velocity $(U)$ profile normalized by the mean velocity measured at the canopy top $\left(U_{h}\right)$. (c) Profile of Reynolds stress $\left(-\left\langle u^{\prime} w^{\prime}\right\rangle\right)$ normalized by the friction velocity $\left(u_{*}^{2}\right)$ measured at the canopy top. (d) Same as (c), but for normalized horizontal velocity variance, $\sigma_{u} / u_{*}$. (e) Same as (c), but for normalized vertical velocity variance, $\sigma_{w} / u_{*}$. (f) Normalized Lagrangian time scale $\left(t_{L} u_{*} / h\right)$ profile as a function of normalized height $(z / h)$. In parts (a)-(e), 'squares' denote measurements and 'solid line' denotes the profile used in the model.

1, 'squares' denote ensemble-averaged measurements over more than 90 sampling runs and 'solid lines' denote the profiles used for driving the Lagrangian models. The formulations of these profiles are summarized in Appendix A. Note that these flow statistical profiles are consistent with several literature values summarized in Raupach et al. (1996).

The $\mathrm{CO}_{2}$ concentration and flux measurements were sampled on September 19,1994 . The mean canopy height at that time was $13 \mathrm{~m}$. The $\mathrm{CO}_{2}$ concentration profiles were measured using a LICOR 6252 gas analyzer at six levels, which were $1 \mathrm{~m}, 3 \mathrm{~m}, 6 \mathrm{~m}, 9 \mathrm{~m}, 12 \mathrm{~m}$, and $19.5 \mathrm{~m}$ above the ground, sequentially. Concentration measurements at each level required $1.25 \mathrm{~min}$ dwell time in order to purge the existing air and for the gas analyzer to determine the one-minute average $\mathrm{CO}_{2}$ concentration. These $\mathrm{CO}_{2}$ concentration time series were combined to construct 

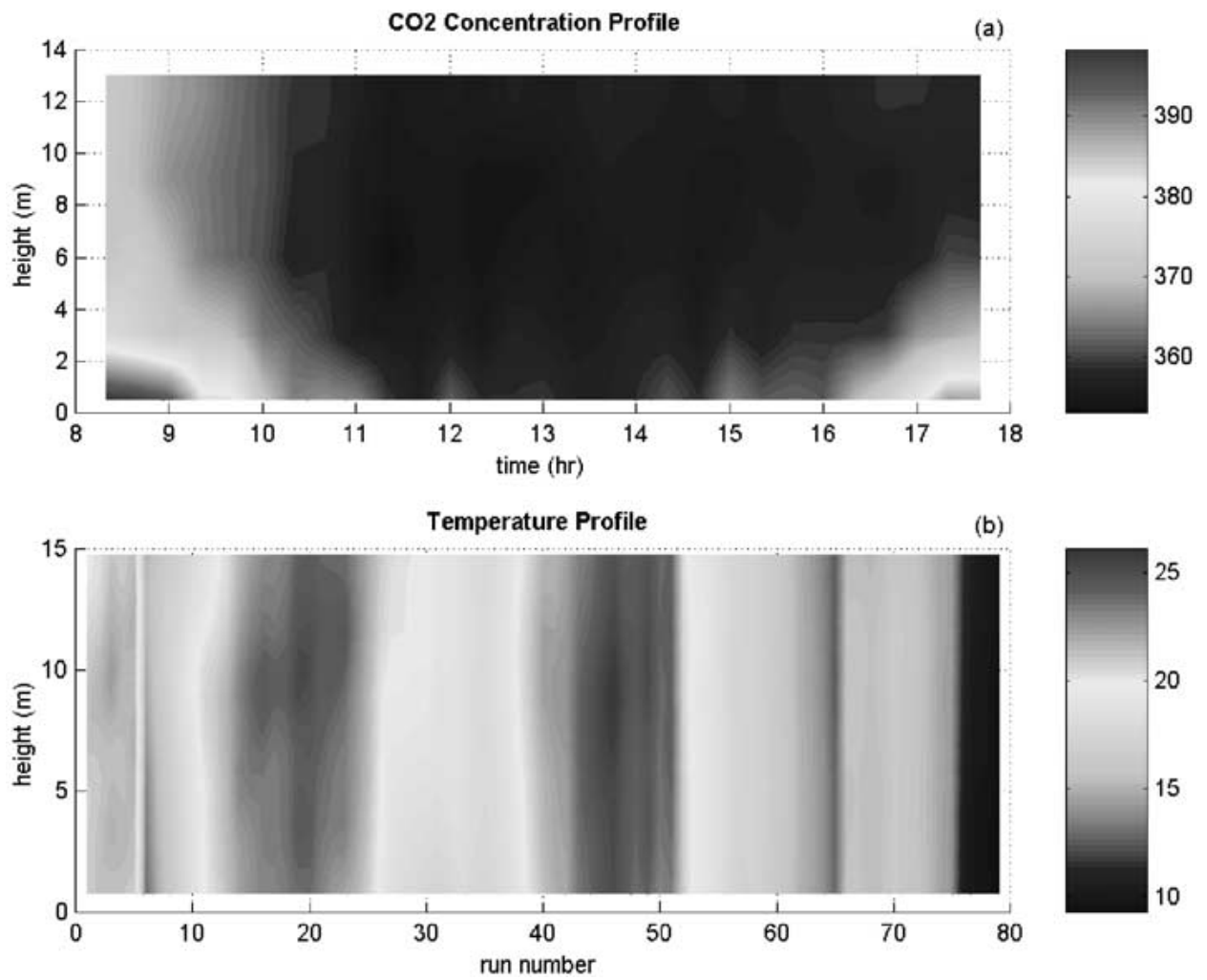

Figure 2. (a) Time variation of mean $\mathrm{CO}_{2}$ concentration measurements (ppm) as a function of height (m). (b) Same as (a), but for mean air temperature $\left({ }^{\circ} \mathrm{C}\right)$.

20-min averages and each level was sampled for approximately 3 min with 1 min at the beginning, $1 \mathrm{~min}$ at the middle, and $1 \mathrm{~min}$ at the end of each 20-min interval.

An eddy-correlation system consisted of a Campbell Scientific (CA27) onedimensional sonic anemometer and a fast-response LICOR $6262 \mathrm{CO}_{2} / \mathrm{H}_{2} \mathrm{O}$ gas analyzer was available at $9 \mathrm{~m}$ to measure the $\mathrm{CO}_{2}$ flux. The three velocity components at the canopy top $(14 \mathrm{~m})$ were also measured using a Gill ultrasonic anemometer. The velocity measurements were rotated so that $U$ is aligned along the mean longitudinal wind direction at the canopy top. Along the mean wind direction, the forest leading edge is $100 \mathrm{~m}$ from this tower. The sampling frequency and period were $10 \mathrm{~Hz}$ and $20 \mathrm{~min}$, respectively. This data set was also used by Katul et al. (1997) to investigate LNF and Katul and Albertson (1999) to investigate their Eulerian closure inverse model.

The measured $\mathrm{CO}_{2}$ concentration (in unit of $\mathrm{ppm}$ ) profile as a function of time and height is shown in Figure 2a. Notice that, from about 1000 to 1600, photosynthesis and turbulent transport are stronger, hence $\mathrm{CO}_{2}$ concentrations were lower and well mixed compared to other times of day. 


\subsection{HEAT DISPERSION EXPERIMENT}

To assess the vertical distribution of sensible fluxes, $\mathrm{H}_{\mathrm{s}}$, inside the canopy, this experiment was conducted between April 19-23, 2000 at another tower within the same pine stand, now part of the Duke AmeriFlux monitoring site (Katul et al., 1999). Along the mean wind direction, the forest leading edge is $560 \mathrm{~m}$ from this tower. The mean canopy height at that time was $14 \mathrm{~m}$. Simultaneous mean air temperature $(\theta)$ profiles and velocity statistics were measured through the canopy. The mean air temperature was measured at 8 levels $(1.5,3.5,5.5,7.5,9.5,11.5$, 13.5 , and $15.5 \mathrm{~m}$ ) using shielded Copper Constantan thermocouples (20 gauge, diameter $=0.812 \mathrm{~mm}$ ). The sampling frequency and duration were $10 \mathrm{~Hz}$ and 30 min, respectively. The measured mean air temperature (in ${ }^{\circ} \mathrm{C}$ ) profile as a function of time and height is shown in Figure 2b. Due to instrument maintenance, there were gaps in the measurements. Hence, we were not able to provide continuous time of day, but run number. The run numbers 1 to 5 were measured from 1330 to 1600, Day 110, the run numbers 6 to 35 were measured from 0830 to 2300, Day 111 , and the run numbers 36 to 79 were measured from 0830 to 2300, Day 112 .

The velocity statistics and heat fluxes were simultaneously measured at 3.0, 4.9, 8.6, 10.9, 12.2, and $15.5 \mathrm{~m}$ above the ground surface using six Campbell Scientific sonic anemometers (CSAT3). The sampling frequency was $10 \mathrm{~Hz}$ and the sampling period for each run was 30 min. Heat flux measurements during transition periods were unsteady and unsuitable for assessing model performance since the key model assumption (steady state) was clearly violated. Hence these unsteady heat flux measurements were filtered out for testing model predictions. The 30-min velocity statistic profiles for $U / U_{h},-\left\langle u^{\prime} w^{\prime}\right\rangle / u_{*}^{2}, \sigma_{u} / u_{*}$, and $\sigma_{w} / u_{*}$ are shown run-by-run in Figures $3 \mathrm{a}$ to $3 \mathrm{~d}$, respectively. The ensemble-averaged velocity statistic profiles over these sampling runs are similar to those in Figure 1 and are not repeated here again. This similarity is expected since these velocity measurements were carried out at the same forest though not on the same tower. The formulations for these ensemble-averaged profiles are also listed in Appendix A. Further details about this experiment can be found in Siqueira et al. (2000).

Run-by-run velocity statistic profiles through the canopy were simultaneously available along with mean temperature and heat flux measurements. Hence, this experiment provides a unique opportunity to examine the differences between two types of simulations, one carried out by driving the model with the run-by-run velocity profiles and the other produced by driving the model with the ensembleaveraged velocity profiles. 

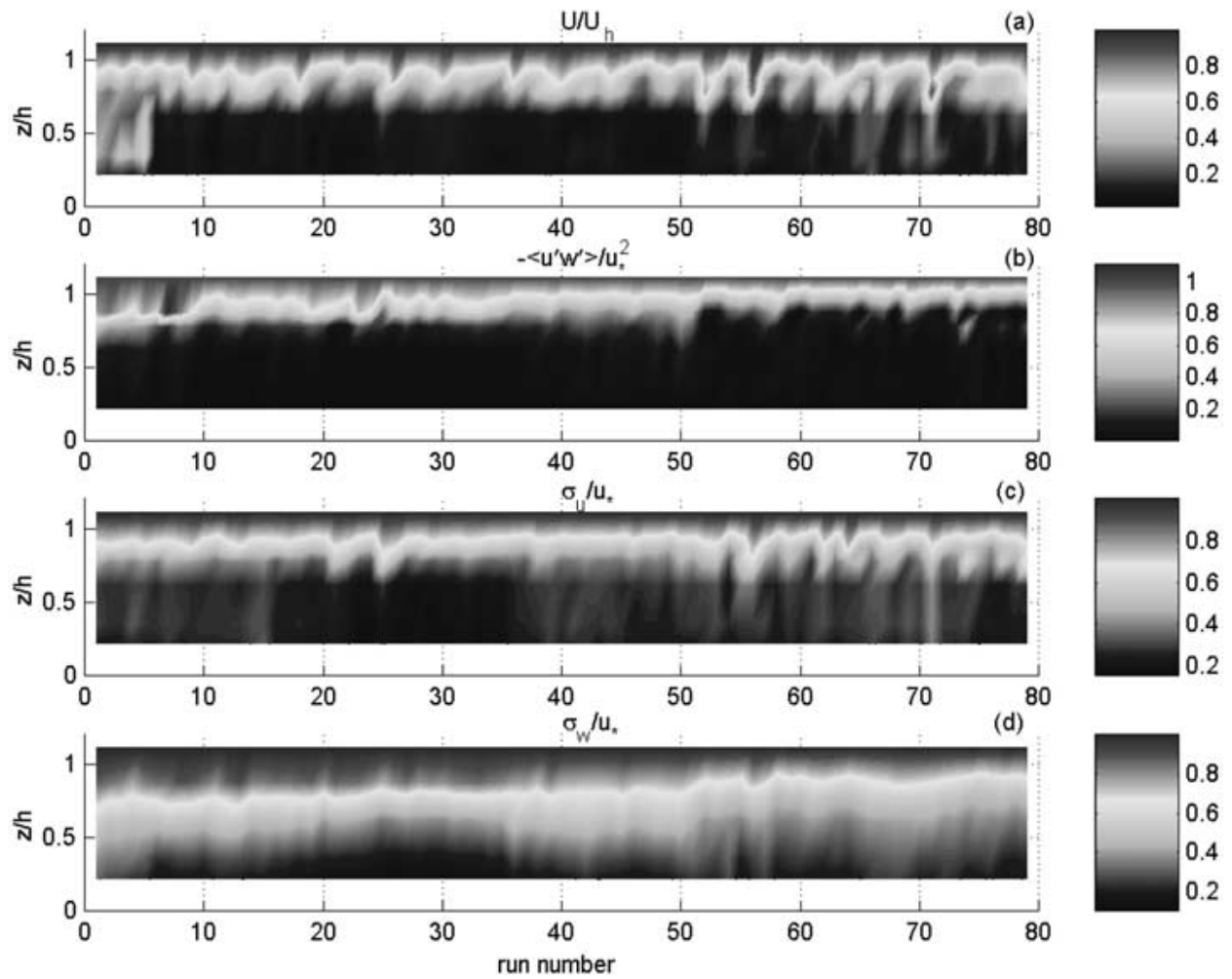

Figure 3. (a) Run-by-run variation of measured $U / U_{h}$ profile. (b) Same as (a), but for $-\left\langle u^{\prime} w^{\prime}\right\rangle / u_{*}^{2}$. (c) Same as (a), but for $\sigma_{u} / u_{*}$. (d) Same as (a), but for $\sigma_{w} / u_{*}$.

\section{Results and Discussion}

\section{1. $\mathrm{CO}_{2}$ DISPERSION SIMULATION}

With the ensemble-averaged flow statistical profiles presented in Figure 1 and measured $\mathrm{CO}_{2}$ concentration profiles shown in Figure 2a, the two-dimensional Lagrangian stochastic dispersion model was used to predict the source-sink (ppm $\mathrm{s}^{-1}$ ) and flux (ppm m s${ }^{-1}$ ) profiles of $\mathrm{CO}_{2}$ as a function of height and time. The predictions are shown in Figures $4 \mathrm{a}$ and $4 \mathrm{~b}$, respectively. Notice that large $\mathrm{CO}_{2}$ sinks occurred between $6 \mathrm{~m}$ to $9 \mathrm{~m}$. Minor $\mathrm{CO}_{2}$ sinks and sources were computed below $6 \mathrm{~m}$. These results suggest that most of the photosynthesis occurred at leaves above $6 \mathrm{~m}$; however, $\mathrm{CO}_{2}$ uptake and release from leaves nearly balanced each other below $6 \mathrm{~m}$. These distributions are consistent with forward calculations of Lai et al. (2000) in which the coupled photosynthesis-radiation model of the canopy was used to compute these source-sink profiles. To further confirm the sourcesink calculations, the measured and predicted $\mathrm{CO}_{2}$ fluxes at $9 \mathrm{~m}$ (i.e., inside the canopy) were compared in time series and scatter plots shown in Figures 5a and 5b. The 'solid line' in Figure 5a represents model prediction and the 'squares' 

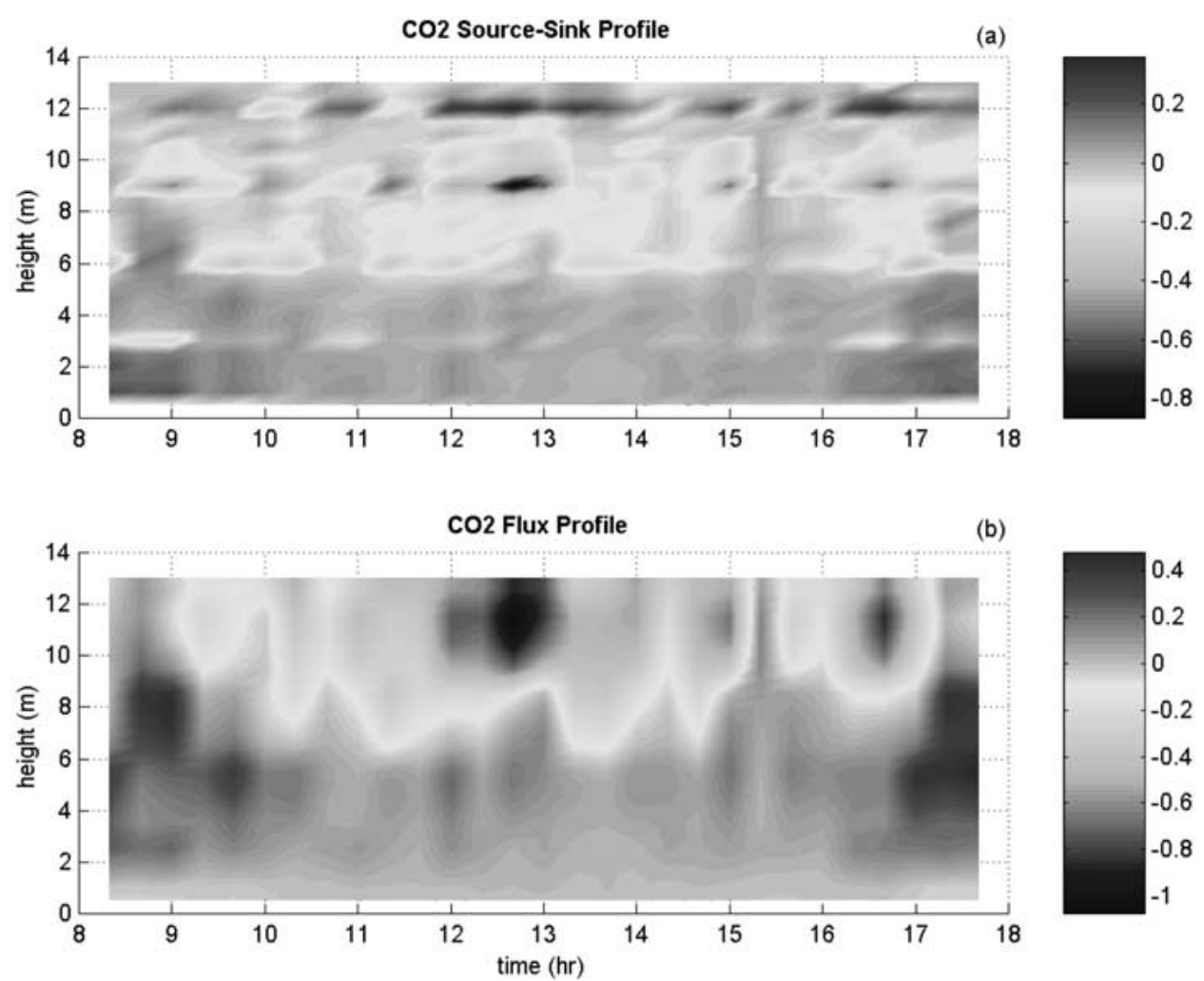

Figure 4. (a) Time variation of $\mathrm{CO}_{2}$ source-sink $\left(\mathrm{ppm} \mathrm{s}^{-1}\right.$ ) profile predicted by the two-dimensional Lagrangian model. (b) Same as (a), but for $\mathrm{CO}_{2}$ flux (ppm m s${ }^{-1}$ ).

denote measurements. In Figure $5 \mathrm{~b}$, the coefficient of determination, $R^{2}$, is 0.42 . It is demonstrated that the model prediction reasonably captures the flux magnitude and temporal evolution within the canopy.

Figures $6 \mathrm{a}$ and $6 \mathrm{~b}$ are the same as Figures $4 \mathrm{a}$ and $4 \mathrm{~b}$, respectively, but the simulations were carried out using the one-dimensional Lagrangian analytical model of Warland and Thurtell (2000). Notice that the modelled patterns of $\mathrm{CO}_{2}$ sourcesink and flux distributions are similar to those computed by the two-dimensional model, but the absolute magnitudes are smaller. The maximum and average differences between simulations by the two models are $63 \%$ and $21 \%$ for source-sink prediction and 53\% and 16\% for fluxes. These differences are not surprising given the assumptions and the computational domains in the two models. Recall that the two-dimensional model explicitly resolves the advective transport. These differences in absolute source and flux magnitudes can also be interpreted in terms of source domain size differences. The predicted source-sink strength for the measured $\mathrm{CO}_{2}$ concentration profile is distributed over the entire source domain for the one-dimensional model but is distributed within a limited source-sink area (limited fetch) in the two-dimensional model. In this case, the fetch is $100 \mathrm{~m}$. The difference 

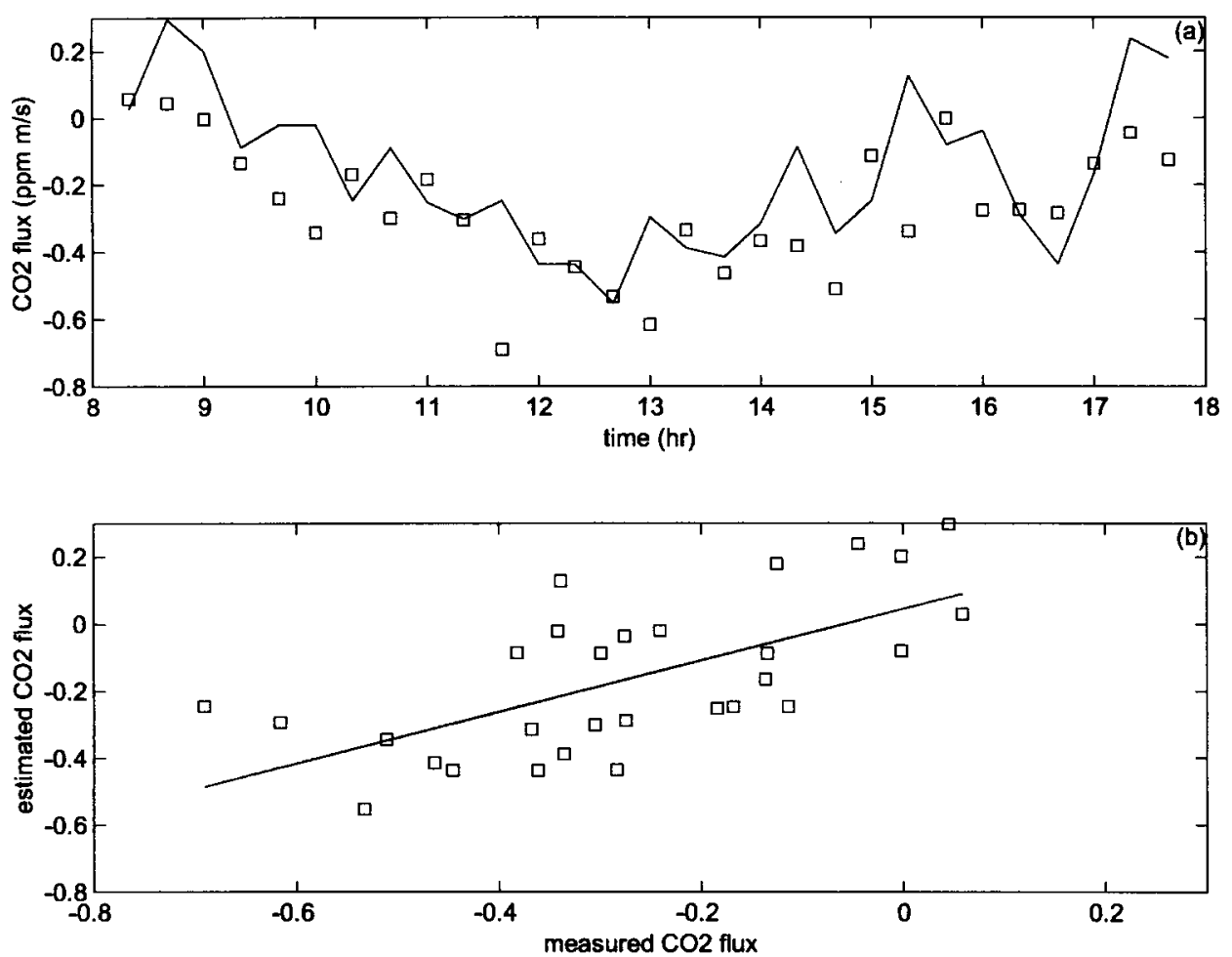

Figure 5. (a) Time series comparison between measured and the two-dimensional Lagrangian model predicted $\mathrm{CO}_{2}$ fluxes at $9 \mathrm{~m}$. 'Squares' denote measurements and 'solid line' represents model prediction. (b) Scatter plot of measured and the two-dimensional Lagrangian model predicted $\mathrm{CO}_{2}$ fluxes at $9 \mathrm{~m}$. 'Solid line' denotes regression line and the coefficient of determination, $\mathrm{R}^{2}$, is 0.42 .

between the two models in flux estimations is smaller than that in source-sink estimations because the source area (or footprint) for concentration is commonly larger than that for flux at the same height (Rannik et al., 2000). Using the onedimensional model, Figures $7 \mathrm{a}$ and $7 \mathrm{~b}$ show the comparisons between measured and predicted $\mathrm{CO}_{2}$ fluxes at $9 \mathrm{~m}$ in time series and scatter plot, respectively. Notice that Figure 7a has the same pattern as Figure $5 \mathrm{a}$ and the $R^{2}$ value is 0.37 in Figure $7 \mathrm{~b}$, which is about the same as that by the two-dimensional model.

To further examine the importance of advection, the two-dimensional model was run for this $\mathrm{CO}_{2}$ dispersion problem under the following conditions: $u_{*}=0.38$ $\left(\mathrm{m} \mathrm{s}^{-1}\right)$, which is a mean value over all runs, 26 point sources (two sources per metre) each with unit source strength, and for different fetches: $x=100 \mathrm{~m}, 200 \mathrm{~m}$, $300 \mathrm{~m}$, and $400 \mathrm{~m}$. Figure $7 \mathrm{c}$ shows the concentration gradient, $\mathrm{d} C / \mathrm{d} z$, as a function of $\mathrm{z} / \mathrm{h}$ for different fetches. It is clear that for $z / h>0.15, \mathrm{~d} C / \mathrm{d} z$ converged very quickly. The biggest difference of $\mathrm{d} C / \mathrm{d} z$ for different fetches happened at the lowest level, but converged around $x=400 \mathrm{~m}$ with increasing fetch. Figure $7 \mathrm{c}$ demonstrates that the advective effect is important for $z / h$ less than 0.15 but can 

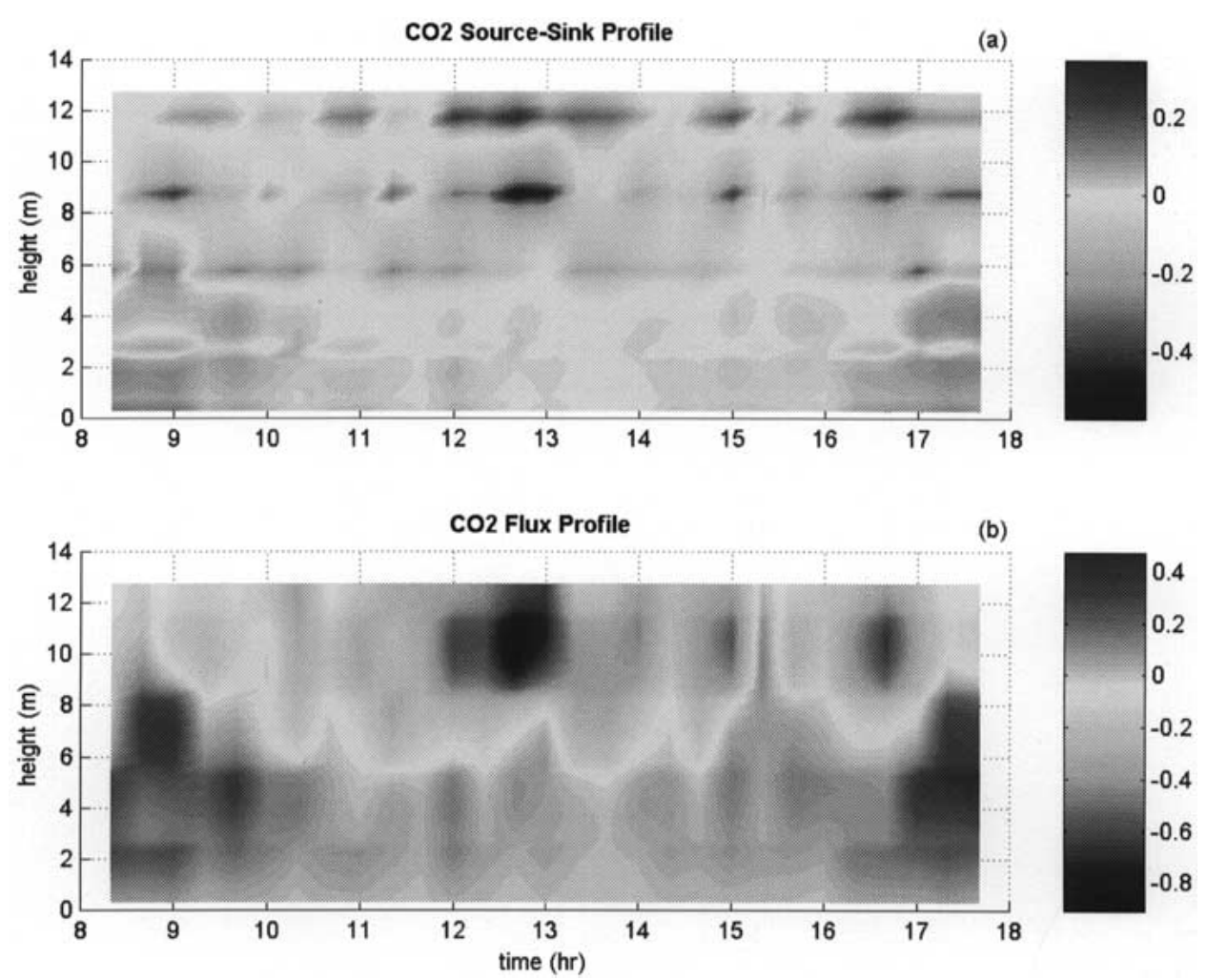

Figure 6. (a) Time variation of $\mathrm{CO}_{2}$ source-sink $\left(\mathrm{ppm} \mathrm{s}^{-1}\right.$ ) profile predicted by the one-dimensional Lagrangian model. (b) Same as (a), but for $\mathrm{CO}_{2}$ flux (ppm m s${ }^{-1}$ ).

be neglected for $z / h>0.15$. This explains why there is little difference between the predictions by the one- and two-dimensional models.

\subsection{HEAT DISPERSION SIMULATION}

The heat dispersion experiment provided six levels of measured sensible heat flux; hence, a more rigorous examination of the model performance is possible. With the ensemble-averaged flow properties shown in Figure 1 and measured temperature profiles presented in Figure 2b, the two-dimensional Lagrangian stochastic model was used to predict the source-sink $\left(\mathrm{W} \mathrm{m}^{-1}\right)$ and flux $\left(\mathrm{W} \mathrm{m}^{-2}\right)$ profiles of heat as a function of height and time. The predictions are shown in Figures $8 \mathrm{a}$ and $8 \mathrm{~b}$, respectively. Using Warland and Thurtell's (2000) one-dimensional model, Figures $9 \mathrm{a}$ and $9 \mathrm{~b}$ present the same profiles as in Figures $8 \mathrm{a}$ and $8 \mathrm{~b}$, respectively. These figures show that, for high sun angles, the top canopy layers are strong heat sources while the remaining layers are heat sinks. Notice the differences between Figure $8 \mathrm{a}$ and $9 \mathrm{a}$ and Figures $8 \mathrm{~b}$ and $9 \mathrm{~b}$ are smaller than those for the $\mathrm{CO}_{2}$ dispersion experiment. The maximum and average differences are $38 \%$ and $14 \%$ for source- 

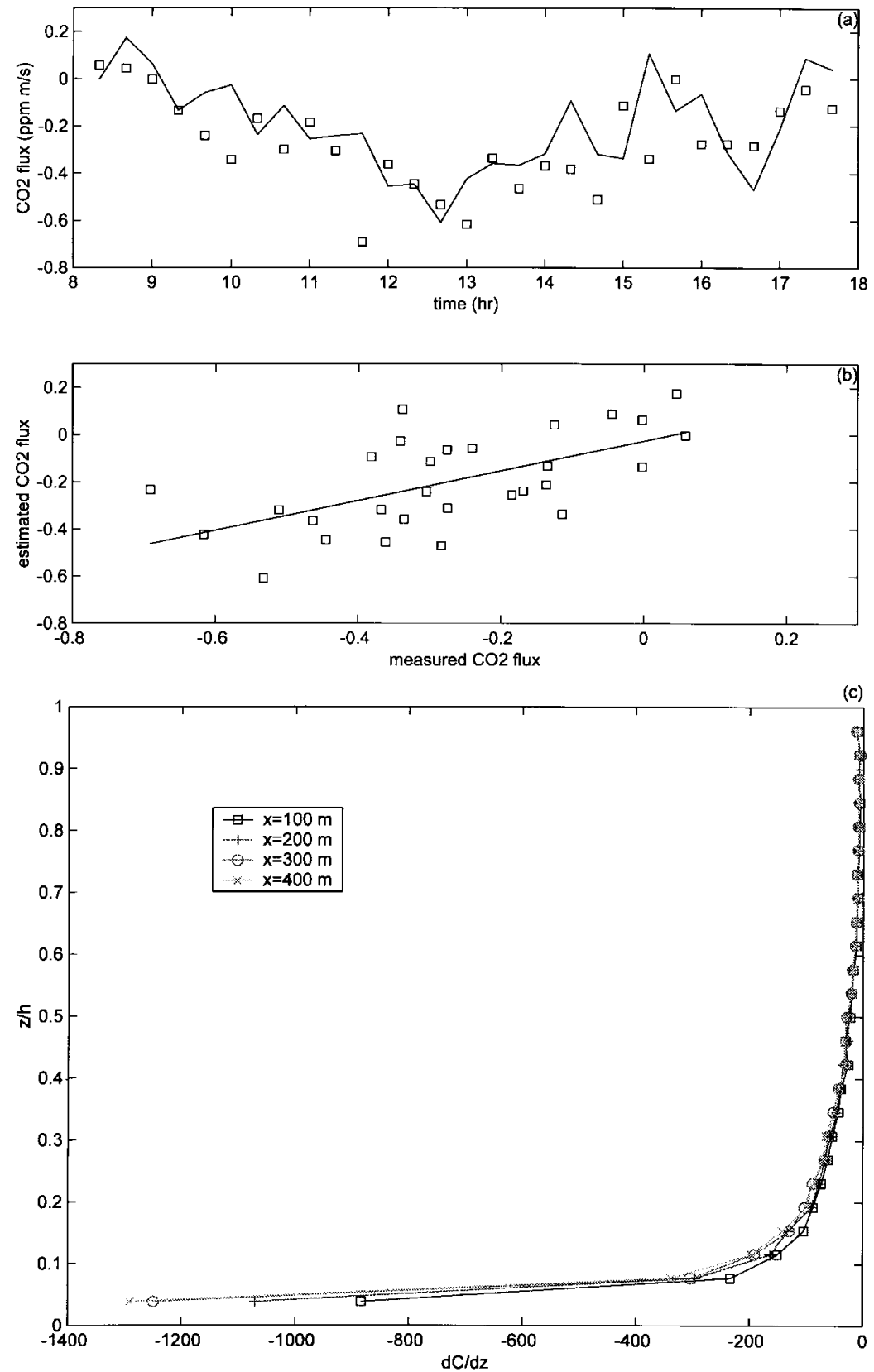

Figure 7. (a) Time series comparison between measured and the one-dimensional Lagrangian model predicted $\mathrm{CO}_{2}$ fluxes at $9 \mathrm{~m}$. 'Squares' denote measurements and 'solid line' represents model prediction. (b) Scatter plot of measured and the one-dimensional Lagrangian model predicted $\mathrm{CO}_{2}$ fluxes at $9 \mathrm{~m}$. 'Solid line' denotes regression line and the coefficient of determination, $\mathrm{R}^{2}$, is 0.37 . (c) Concentration gradient profile $(\mathrm{d} C / \mathrm{d} z)$ as a function of normalized height $(z / h)$ for different fetches: $x=100,200,300$, and $400 \mathrm{~m}$. 

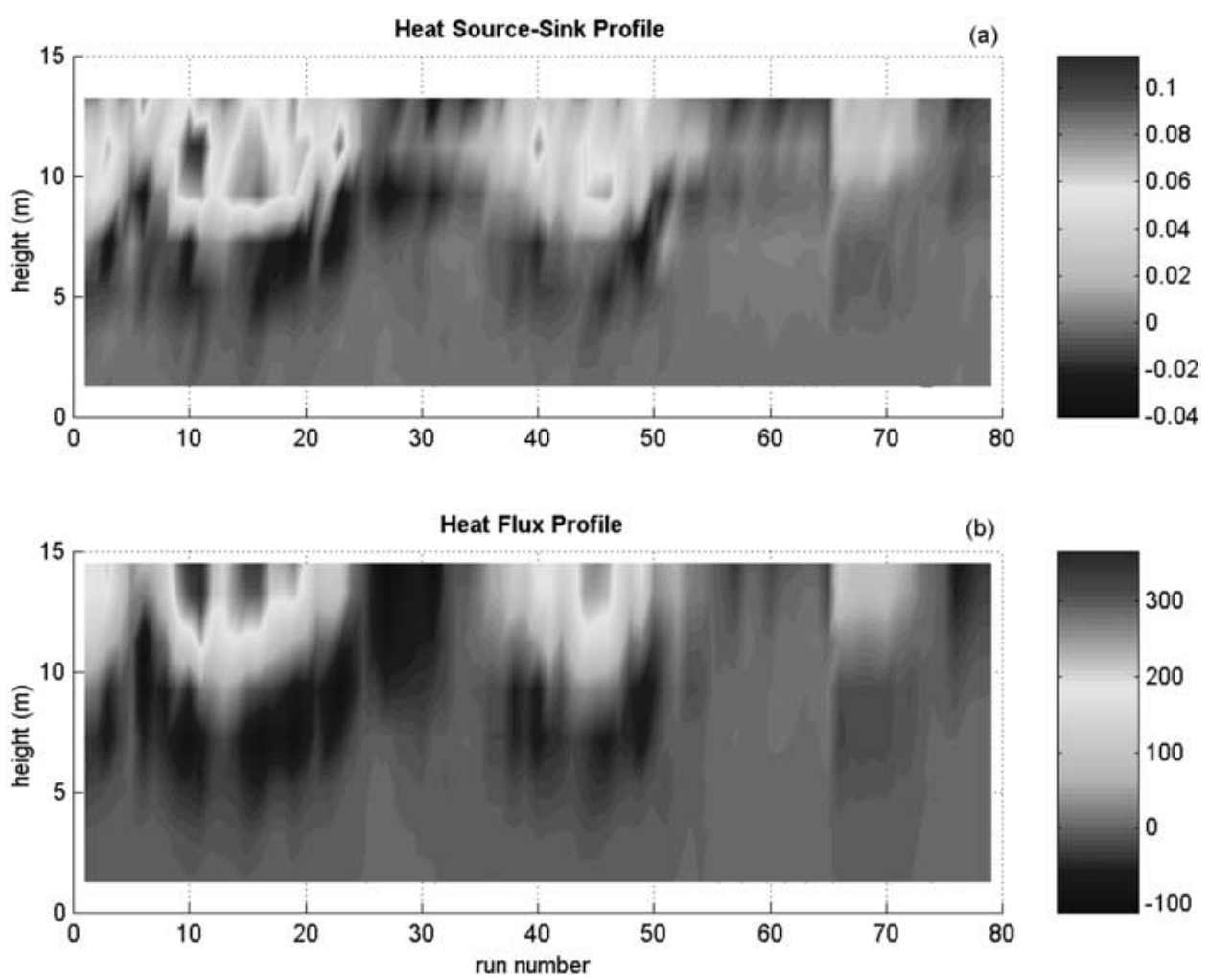

Figure 8. (a) Variation of heat source-sink $\left(\mathrm{W} \mathrm{m}^{-1}\right)$ profile predicted by the two-dimensional Lagrangian model. (b) Same as (a), but for heat flux $\left(\mathrm{W} \mathrm{m}^{-2}\right)$.

sink predictions and $21 \%$ and $14 \%$ for fluxes. These results also demonstrate that the advective effect becomes less and less when the fetch is longer (in this case the fetch is $560 \mathrm{~m}$ ).

Figure 10a shows the time variation of eddy-correlation measured sensible heat flux profiles within the forest canopy. Comparison between predicted sensible heat flux profiles (Figures $8 \mathrm{~b}$ and $9 \mathrm{~b}$ ) and the measurements (Figure 10a) show that the two models captured the major events. Figure $10 \mathrm{~b}$ shows the sensible heat flux $\left(H_{s}\right)$ gradient comparison between the averaged flux measurements and averaged model predictions at the six measurement layers. It is demonstrated that the predictions match with the measurements. To further examine the model performance, scatter plots of measured sensible heat fluxes versus the two-dimensional and onedimensional model predictions are shown in Figures 10c and 10d, respectively. The coefficient of determination $\left(R^{2}\right)$ is 0.84 for both of the two model predictions. These comparisons show that both the two models capture the flux measurements well. 

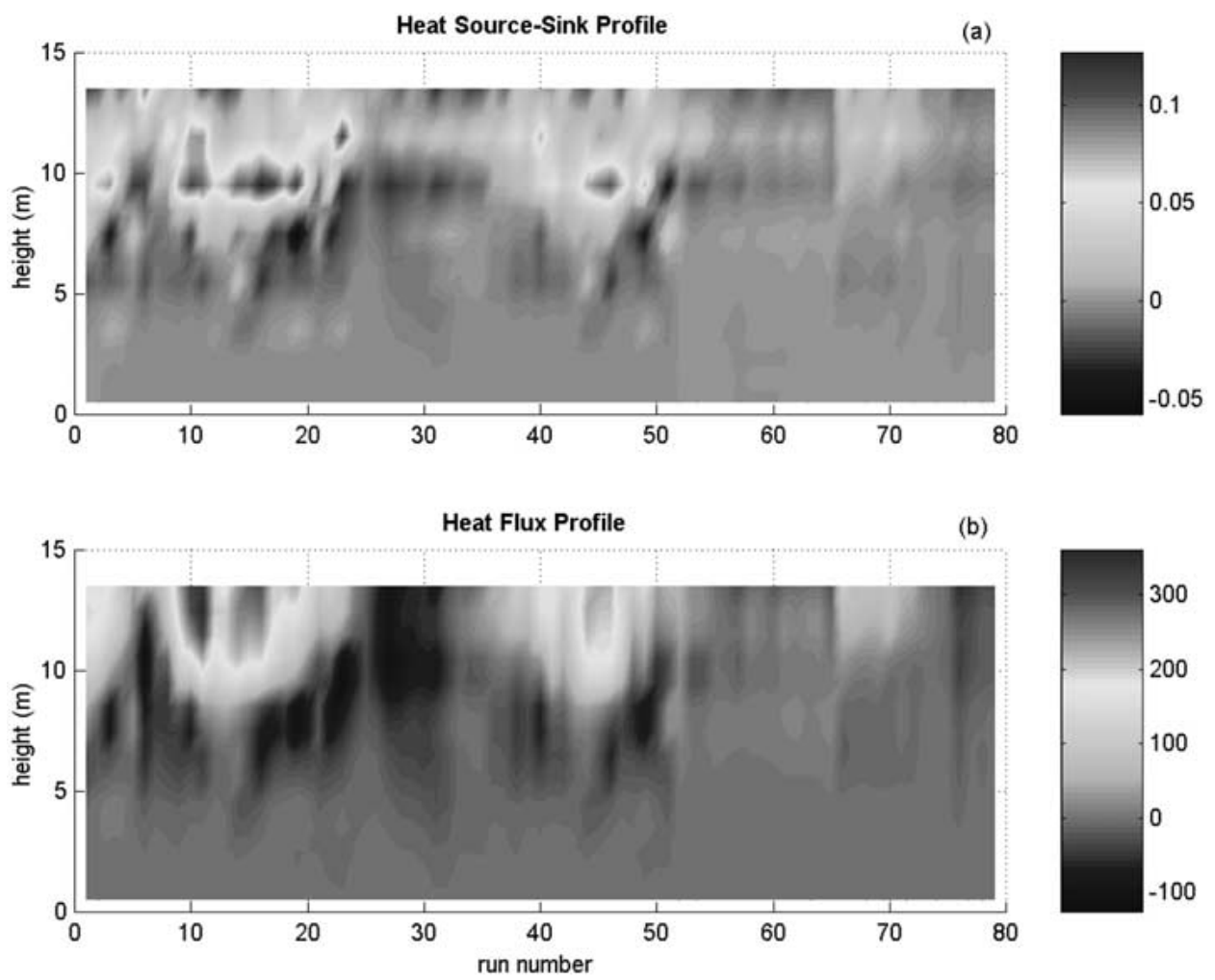

Figure 9. (a) Variation of heat source-sink $\left(\mathrm{W} \mathrm{m}^{-1}\right)$ profile predicted by the one-dimensional Lagrangian model. (b) Same as (a), but for heat flux $\left(\mathrm{W} \mathrm{m}^{-2}\right)$.

\subsection{EFFECTS OF VELOCITY STATISTICAL PROFILES}

Flow statistics are required for driving both the Lagrangian stochastic and analytical models. Generally, individual run-by-run velocity statistic profiles are not available and ensemble-averaged velocity statistic profiles (averaged over many sampling runs) are used. As earlier stated, the ensemble-averaged profile does not explicitly resolve the effects of local atmospheric stability on flow properties but the individual run-by-run profile does. The heat dispersion experiment provides a unique opportunity to evaluate whether any improvement in model performance is achieved by using individual run-by-run flow statistics to drive the models. Recall, for each sampling run of the heat dispersion experiment, velocity measurements were conducted simultaneously with mean temperature and sensible heat flux. Using the individual run-by-run velocity statistics profile shown in Figure 3, the two-dimensional Lagrangian stochastic model was used to predict the heat sourcesink and flux profiles shown in Figures 11a and 11b. Comparison between Figures $8 \mathrm{~b}, 10 \mathrm{a}$, and $11 \mathrm{~b}$ shows that using the run-by-run velocity profiles to drive the model does not improve the predictions of heat fluxes. Using Warland and Thur- 

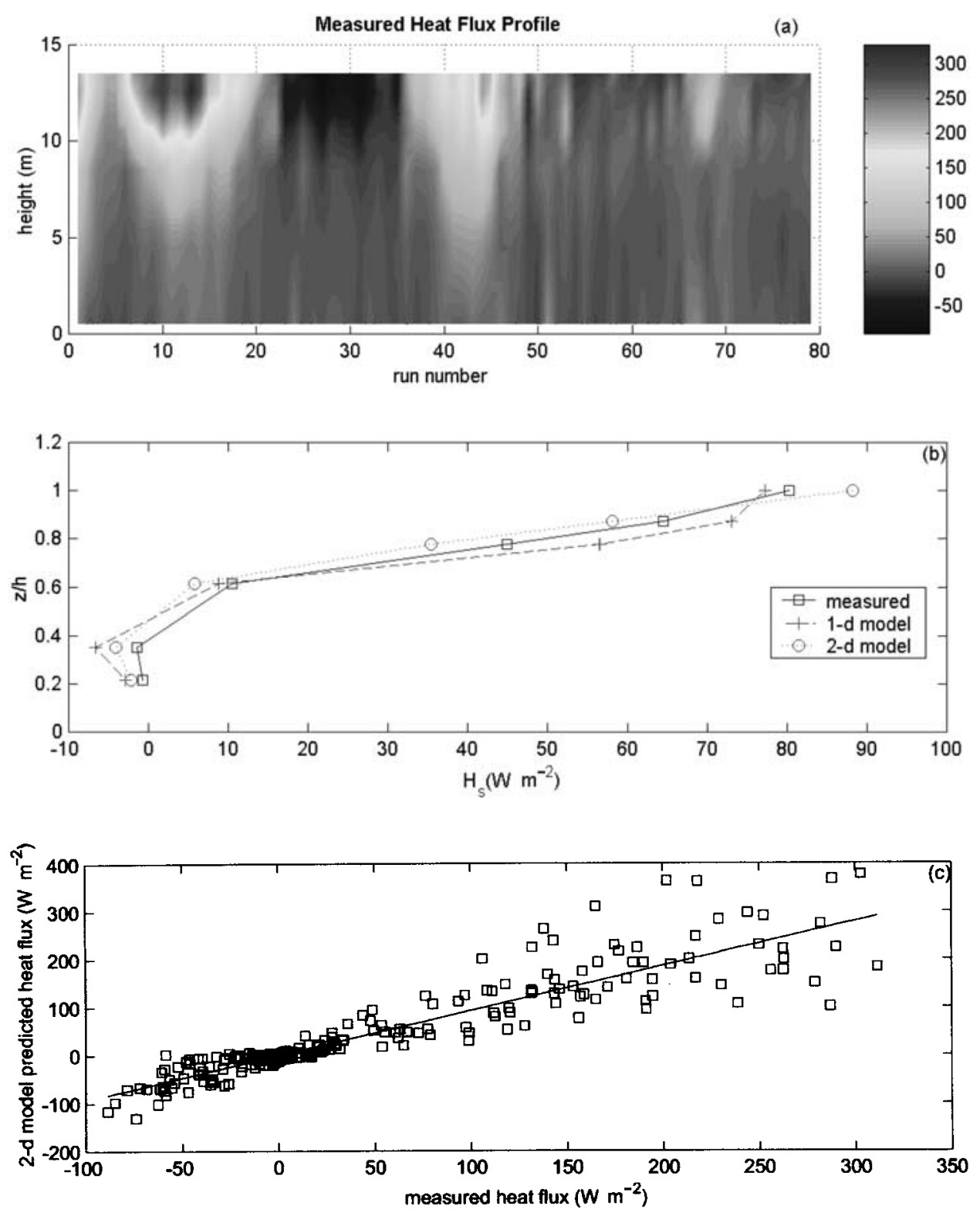

Figure 10. (a) Variation of measured heat flux $\left(\mathrm{W} \mathrm{m}^{-2}\right)$ profile. (b) Comparison between measured and predicted sensible heat fluxes $\left(H_{S}\right)$ as a function of normalized height $(z / h)$. 'Square' denotes measurement, 'Plus' denotes the two-dimensional model prediction, and 'Circle' denotes the one-dimensional estimation. (c) Scatter plot of measured and the two-dimensional Lagrangian model predicted heat fluxes. 'Solid line' denotes regression line and the coefficient of determination, $R^{2}$, is 0.84 . (d) Scatter plot of measured and the one-dimensional Lagrangian model predicted heat fluxes. 'Solid line' denotes regression line and the coefficient of determination, $R^{2}$, is 0.84 . 


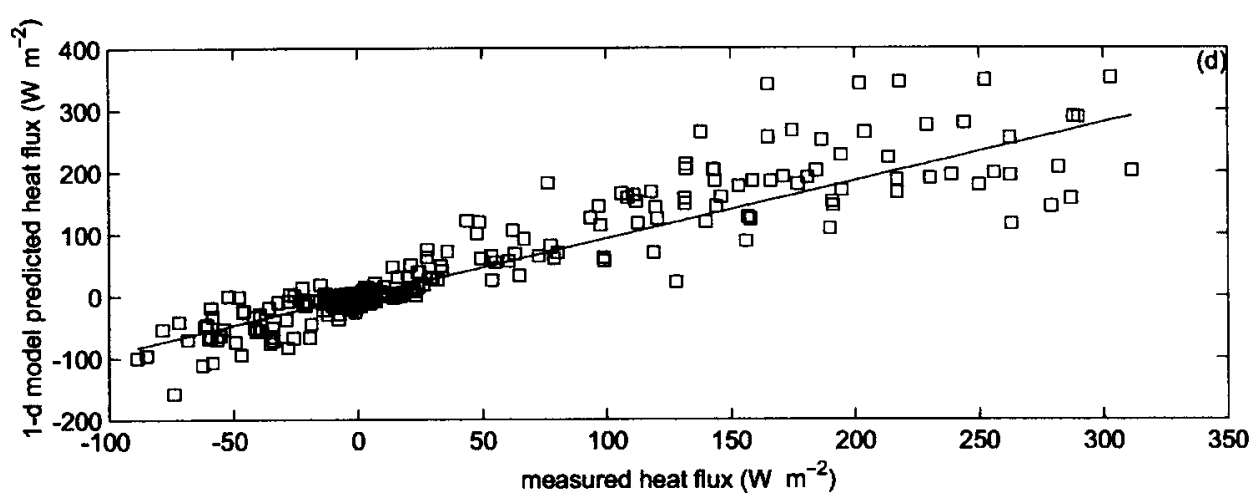

Figure 10. Continued.

tell's (2000) one-dimensional model driven by the run-by-run velocity profiles, Figures $12 \mathrm{a}$ and $12 \mathrm{~b}$ present predicted heat source-sink and flux profiles, respectively. As in the two-dimensional model, Figure 12b does not show any marked improvement when compared to Figure 9b, where the calculations were carried out with ensemble-averaged velocity statistic profiles shown in Figure 1. One explanation is that the individual run-by-run velocity profiles do not faithfully represent the proper spatial averaging of flow field. However, the ensemble-averaged profiles, by the ergodic hypothesis (Monin and Yaglom, 1971), may closely converge to the spatially averaged profile. An immediate consequence is that detailed accounting for atmospheric stability in the velocity statistics profiles may not be the critical factor needed to improve source-sink estimations inferred from concentration measurements.

A broad spectrum of numerical models ranging from Lagrangian stochastic (based on Markov assumption), Lagrangian analytical (LNF and Warland and Thurtell's, both based on Taylor's dispersion theory), and Eulerian (based on turbulent flux budget equation) models are now available and field-tested with comparable data. While these models are derived using different theoretical formulations, the comparison between $\mathrm{CO}_{2}$ fluxes by LNF (Figure 6 in Katul et al., 1997), Eulerian model (Figure 2 in Katul and Albertson, 1999) and Lagrangian stochastic and analytical models (Figures 5 and 7 in this study) show that they tend to produce very similar flux profiles (for the same data set). These models share only the same $\mathrm{CO}_{2}$ concentration profiles. Hence, scalar concentration profiles should be the dominant factor determining the accuracy of the inverse problems.

\section{Conclusions}

For the forest canopy scalar source-sink and flux estimations, the two-dimensional Lagrangian stochastic model presented here and the one-dimensional Lagrangian analytical model proposed by Warland and Thurtell (2000) are able to capture 

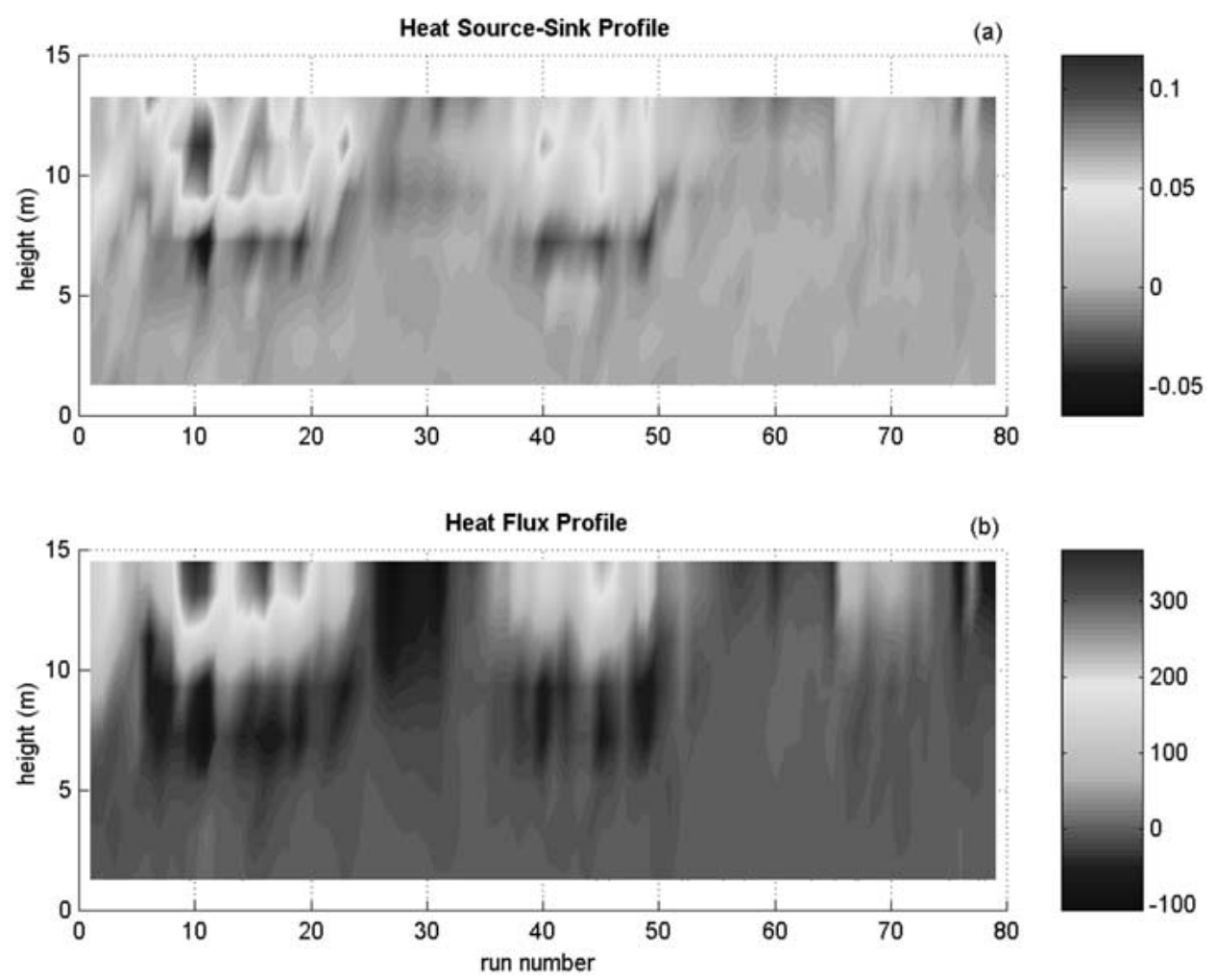

Figure 11. (a) Same as Figure 8a, but the two-dimensional model was driven with the run-by-run velocity statistic profiles shown in Figure 3. (b) Same as Figure 8b, but the two-dimensional model was driven with the run-by-run velocity statistic profiles shown in Figure 3.

key source-sink and flux variations in time and space. These simulations provide detailed information for understanding the relationship between the biophysical sources and sinks and the canopy microclimate. Our study demonstrated the following:

1. The one-dimensional and two-dimensional models produce similar predictions. The major disadvantage of the two-dimensional Lagrangian stochastic model is its large computational time. For the case shown in Figure 8, this stochastic model (random-walk particle trajectories) took a Sun-3000 workstation more than $18 \mathrm{~h}$ to generate the results, while the one-dimensional analytical model needed few seconds. Hence, for long-term estimation of source-sink simulations, Warland and Thurtell's model is recommended over the two-dimensional model.

2. Good agreement between the two models further confirms the robustness of applying a homogeneous solution to describing the inhomogeneity in canopy turbulence. This fact is important to LNF and Warland and Thurtell's (2000) model. 

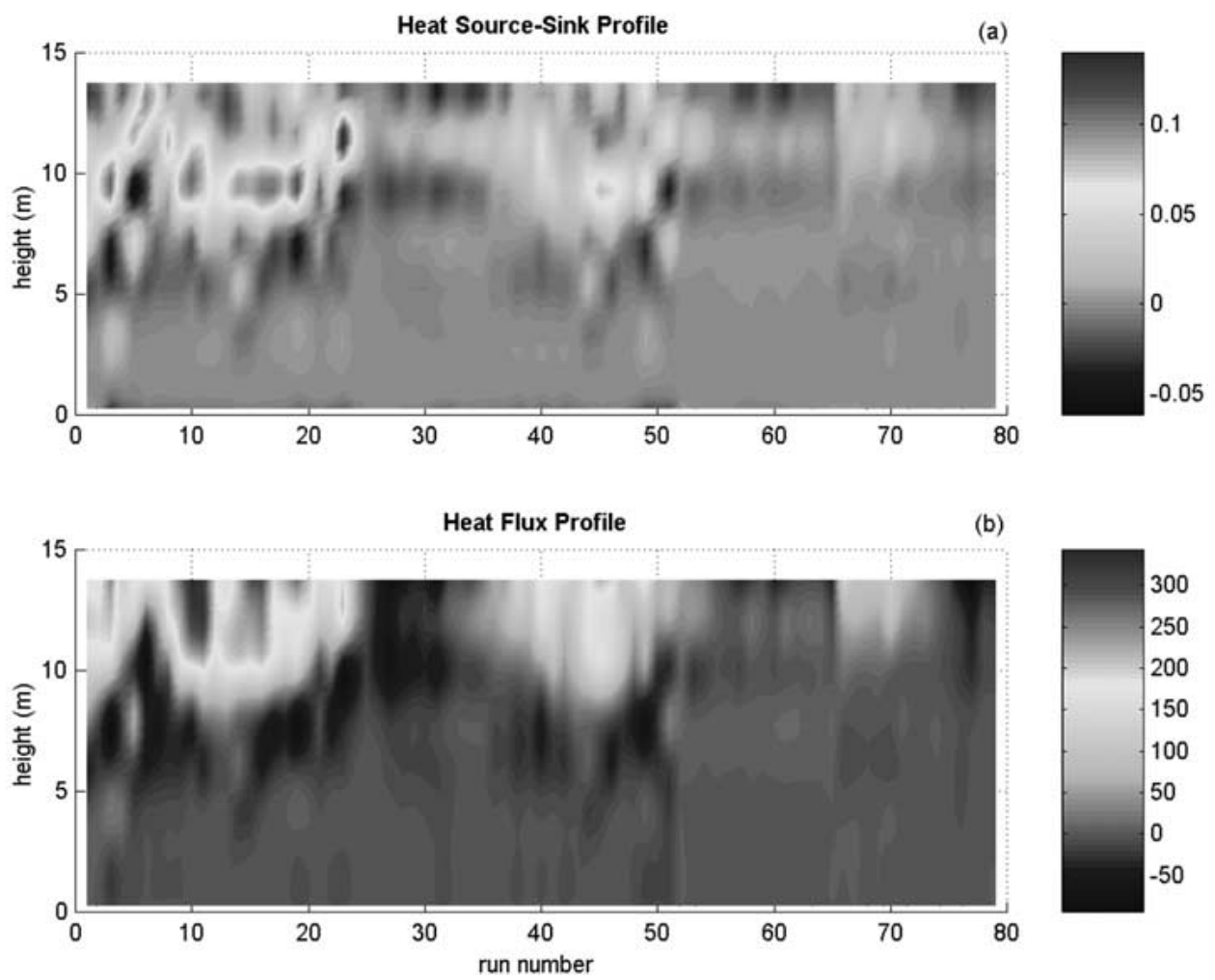

Figure 12. (a) Same as Figure 9a, but the one-dimensional model was driven with the run-by-run velocity statistic profiles shown in Figure 3. (b) Same as Figure 9b, but the one-dimensional model was driven with the run-by-run velocity statistic profiles shown in Figure 3.

3. Using run-by-run velocity statistics to drive the Lagrangian model does not produce better scalar source-sink and flux predictions than using the ensembleaveraged velocity statistics. This analysis suggests that accounting for local stability effects on the velocity field may not substantially contribute to improvements in the source-sink estimations. Notice that Siqueria and Katul (2002) showed that local stability effects on scalar field are important when using a Eulerian approach to estimate source-sink profiles.

4. When using the two-dimensional Lagrangian stochastic, LNF, Eulerian, or Warland and Thurtell's model for predicting scalar source-sink distributions, scalar concentration profile should be the dominant factor. Hence, fine resolution of concentration gradient measurements should be necessary for improving model predictions.

Besides using first-order measurements (i.e., mean concentration) to predict sources-sinks and fluxes, these quantities could be inferred from second-order measurements (i.e., concentration variance). Following the early work by Novikov (1963), Gifford (1982), and Lee and Stone (1983), Reynolds (1998c) proposed a 
two-particle trajectory Lagrangian model to link scalar source to its concentration variance. Hence, Reynolds's model also provides a mean to predict scalar sourcessinks from second-order measurements. Future research effort should be devoted to investigating how this 'second-order measurements' approach works for such problems.

\section{Acknowledgements}

The authors would like to thank the two anonymous reviewers for their helpful comments. This project was funded, in part, by the National Science Council (NSC), Taiwan. The second author is supported by the 'Conselho National de Desenvolvimento Cientifico e Tecnologico (CNPq)' of Brazil. The data for this project were funded, in part, by the U.S. Department of Energy (DOE) through the FACE-FACTS project under contract DE-FG05-95ER62083, the Terrestrial Carbon Processes (TCP) project, and through the National Institute for Global Environmental Change (NIGEC), Southeast Regional Center at the University of Alabama, Tuscaloosa (DOE cooperative agreement DE-FC030-90ER61010). Additional support is provided by the National Science Foundation (NSF-BIR 95-12333 and EAR-9805395).

\section{Appendix A: Formulations for Velocity Statistical and Lagrangian Time Scale Profiles}

1. Mean velocity profile

$$
\begin{array}{ll}
U(z)=\left(u_{*} / k\right) \ln \left((z-d) / z_{o}\right) & \text { for } z \geq h \\
U(z) / U(h)=\exp \left(a_{1}(1-z / h)\right) & \text { for } z<h
\end{array}
$$

2. Velocity covariance (Reynolds stress) profile

$$
\begin{aligned}
& -\langle u w\rangle=-u_{*}^{2} \\
& \text { for } z \geq h \\
& -\langle u w\rangle=\left(a_{2} z / h-a_{3}\right)\left(-u_{*}^{2}\right) \\
& \text { for } 0.45 h \leq z<h \\
& -\langle u w\rangle=\left(0.45 a_{2}-a_{3}\right)\left(-u_{*}^{2}\right)
\end{aligned}
$$

3. Horizontal velocity variance profile

$$
\begin{array}{ll}
\sigma_{u}=a_{4} u_{*} & \text { for } z \geq h \\
\sigma_{u}=a_{4} u_{*} \exp \left(a_{5}(1-z / h)\right) & \text { for } z<h
\end{array}
$$

4. Vertical velocity variance profile

$$
\begin{array}{cc}
\sigma_{w}=a_{6} u_{*} & \text { for } z \geq h \\
\sigma_{w}=a_{6} u_{*}\left(0.5\left(a_{6}+a_{7}\right)+\right. & \text { for } z<h \\
\left.0.5\left(a_{6}-a_{7}\right)(-\cos (\pi z / h))\right) &
\end{array}
$$

5. Lagrangian time scale profile

$$
t_{L}=\max \left(a_{8} u_{*} / h, k(z-d) u_{*} / \sigma_{w}^{2}\right) .
$$


Here, $a_{1}, a_{2}, a_{3}, a_{4}, a_{5}, a_{6}, a_{7}$, and $a_{8}$ are constants, $k(=0.4)$ is Von Karman constant, $d(\approx 0.67 h)$ is the zero-plane displacement, and $z_{0}(\approx 0.1 h)$ is the roughness height. For $\mathrm{CO}_{2}$ dispersion experiment, $a_{1}=-3, a_{2}=1.79, a_{3}=0.79, a_{4}=2.0$, $a_{5}=-2, a_{6}=1.2, a_{7}=0.07$, and $a_{8}=0.3$. For heat dispersion experiment, $a_{1}=-4, a_{2}=1.79, a_{3}=0.79, a_{4}=2.0, a_{5}=-2, a_{6}=1.15, a_{7}=0.1$, and $a_{8}=0.1$. In addition, measured mean vertical velocities $(W)$ were close to zero; hence, $W(z)=0$ was used in both experiments. These constants for the profiles were chosen from trial and error to fit the measurements.

\section{References}

Ayotte, K. W., Finnigan, J. J., and Raupach, M. R.: 1999, 'A Second-Order Closure for Neutrally Stratified Vegetative Canopy Flows', Boundary-Layer Meteorol. 90, 189-216.

Borgas, M. S., Flesch, T. K., and Sawford, B. L.: 1997, 'Turbulent Dispersion with Broken Reflexional Symmetry', J. Fluid Mech. 332, 141-156.

Coppin, P. A., Raupach, M. R., and Legg, B. J.: 1986, 'Experiments on Scalar Dispersion within a Model Plant Canopy. Part II: An Elevated Plane Source', Boundary-Layer Meteorol. 35, 167191.

Denmead, O. T., 1995, 'Novel Meteorological Methods for Measuring Trace Gas Fluxes', Phil. Trans. Roy. Soc. Lond. A 351, 383-396.

Ellsworth, D. S., Oren, R., Huang, C., Phillips, N., and Hendrey, G. R.: 1995, 'Leaf and Canopy Responses to Elevated $\mathrm{CO}_{2}$ in a Pine Forest under Free-Air $\mathrm{CO}_{2}$ Enrichment', Oecologia 104, 139-146.

Falge, E., Baldocchi, D., Olson, R., Anthoni, P., Aubinet, M., Bernhofer, C., Burba, G., Ceulemans, R., Clement, R., Dolman, H., Granier, A., Gross, P., Grünwald, T., Hollinger, D., Jenson, N-O., Katul, G., Keronen, P., Kowalski, A., Lai, C. T., Law, B. E., Meyers, T., Moncrief, J., Moors, E., Munger, J. W., Pilegaard, K., Rannik, U., Rebmann, C., Sukyer, A., Tenhunen, J., Tu, K., Verma, S., Vesala, T., Wilson, K., and Wofsy, S.: 2001a, 'Gap Filling Strategies for Long Term Energy Flux Data Sets, A Short Communication', Agric. For. Meteorol. 107, 71-77.

Falge, E., Baldocchi, D., Olson, R., Anthoni, P., Aubinet, M., Bernhofer, C., Burba, G., Ceulemans, R., Clement, R., Dolman, H., Granier, A., Gross, P., Grünwald, T., Hollinger, D., Jenson, N-O., Katul, G., Keronen, P., Kowalski, A., Lai, C. T., Law, B. E., Meyers, T., Moncrief, J., Moors, E., Munger, J. W., Pilegaard, K., Rannik, U., Rebmann, C., Sukyer, A., Tenhunen, J., Tu, K., Verma, S., Vesala, T., Wilson, K., and Wofsy, S.: 2001b, 'Gap Filling Strategies for Defensible Annual Sums of Net Ecosystem Exchange', Agric. For. Meteorol. 107, 43-69.

Gifford, F. A.: 1982, 'Horizontal Diffusion in the Atmosphere: A Lagrangian Dynamical Theory', Atmos. Environ. 16, 505-512.

Kaiser, J.: 1998, 'Climate Change - New Network Aims to Take the Worlds $\mathrm{CO}_{2}$ Pulse Source', Science 281, 506-507.

Katul, G. G. and Albertson, J. D.: 1998, 'An Investigation of Higher-Order Closure Models for a Forested Canopy', Boundary-Layer Meteorol. 89, 47-74.

Katul, G. G. and Albertson, J. D.: 1999, 'Modeling $\mathrm{CO}_{2}$ Sources, Sinks, and Fluxes within a Forest Canopy', J. Geophys. Res. 104, 6081-6091.

Katul, G. G. and Chang, W. H.: 1999, 'Principal Length Scales in Second-Order Closure Models for Canopy Turbulence', J. Appl. Meteorol. 38, 1631-1643.

Katul, G. G., Hsieh, C. I., Bowling, D., Clark, K., Shurpali, N., Turnipseed, A., Albertson, J., Tu, K., Hollinger, D., Evans, B., Offerle, B., Anderson, D., Ellsworth, D., Vogel, C., and Oren, R.: 
1999, 'Spatial Variability of Turbulent Fluxes in the Roughness Sublayer of an Even-Aged Pine Forest', Boundary-Layer Meteorol. 93, 1-28.

Katul, G. G., Leuning, R., Kim, J., Denmead, O. T., Miyata, A., and Harazono, Y.: 2001, 'Estimating $\mathrm{CO}_{2}$ Source/Sink Distributions within a Rice Canopy Using Higher-Order Closure Models', Boundary-Layer Meteorol. 98, 103-125.

Katul, G. G., Oren, R., Ellsworth, D., Hsieh, C. I., Philips, N., and Lewin, K.: 1997, 'A Lagrangian Dispersion Model for Predicting $\mathrm{CO}_{2}$ Sources, Sinks, and Fluxes in a Uniform Loblolly Pine (Pinus Taeda L.) Stand', J. Geophys. Res. 102, 9309-9321.

Kurbanmuradov, O. and Sabelfeld, K.: 2000, 'Lagrangian Stochastic Models for Turbulent Dispersion in the Atmospheric Boundary Layer', Boundary-Layer Meteorol. 97, 191-218.

Lai, C. T., Katul, G. G., Oren, R., Ellsworth, D., and Schäfer, K.: 2000, 'Modeling $\mathrm{CO}_{2}$ and Water Vapor Turbulent Flux Distributions within a Forest Canopy', J. Geophys. Res. 105, 26333-26351.

Lee, J. T. and Stone, G. L.: 1983, 'The Use of Eulerian Initial Conditions in a Lagrangian Model of Turbulent Diffusion', Atmos. Environ. 17, 2477-2481.

Leuning, R.: 2000, 'Estimation of Scalar Source/Sink Distributions in Plant Canopies Using Lagrangian Dispersion Analysis: Corrections for Atmospheric Stability and Comparison with a Multilayer Canopy Model', Boundary-Layer Meteorol. 96, 293-314.

Leuning, R., Denmead, O. T., Miyata, A., and Kim, J.: 2000, Source/Sink Distributions of Heat, Water Vapor, Carbon Dioxide, and Methane in a Rice Canopy Estimated Using Lagrangian Dispersion Analysis', Agric. For. Meteorol. 103, 233-249.

Massman, W. J. and Weil, J. C.: 1999, 'An Analytical One-Dimensional Second-Order Closure Model of Turbulence Statistics and the Lagrangian Time Scale within and above Plant Canopies of Arbitrary Structure', Boundary-Layer Meteorol. 91, 81-107.

Monin, A. S. and Yaglom, A. M.: 1971, Statistical Fluid Mechanics, MIT Press, Cambridge, MA, pp. 215-249, 769 pp.

Novikov, E. A.: 1963, 'Random Force Method in Turbulence Theory', Sov. Phys. J. Exp. Theor. Phys. 17, 1449-1454.

Press, W. H., Teukolsky, S. A., Vettering, W. T., and Flannery, B. P.: 1992, Numerical Recipes in FORTRAN, 2nd edn., Cambridge University Press, Cambridge, 963 pp.

Rannik, U., Aubinet, M., Kurbanmuradov, O., K. Sabelfeld, K. K., Markkanen, T., and Vesala, T.: 2000, 'Footprint Analysis Measurements over a Heterogeneous Forest', Boundary-Layer Meteorol. 97, 137-166.

Raupach, M. R.: 1989a, 'A Practical Lagrangian Method for Relating Scalar Concentrations to Source Distributions in Vegetation Canopy', Quart. J. Roy. Meteorol. Soc. 115, 609-632.

Raupach, M. R.: 1989b, 'Applying Lagrangian Fluid Mechanics to Infer Scalar Source Distributions from Concentration Profiles in Plant Canopies', Agric. For. Meteorol. 47, 85-108.

Raupach, M. R., Finnigan, J. J., and Brunet, Y.: 1996, 'Coherent Eddies and Turbulence in Vegetation Canopies: The Mixing-Layer Analogy', Boundary-Layer Meteorol. 78, 351-382.

Reynolds, A. M.: 1998a, 'On the Formation of Lagrangian Stochastic Models of Scalar Dispersion within Plant Canopies', Boundary-Layer Meteorol. 86, 333-344.

Reynolds, A. M.: 1998b, 'On Trajectory Curvature as a Selection Criterion for Valid Lagrangian Stochastic Dispersion Models', Boundary-Layer Meteorol. 88, 77-86.

Reynolds, A. M.: 1998c, 'A Lagrangian Stochastic Model for the Trajectories of Particle Pairs and Its Application to the Prediction of Concentration Variance within Plant Canopies', Boundary-Layer Meteorol. 88, 467-478.

Rodean, H.: 1996, Stochastic Lagrangian Models of Turbulent Diffusion, Meteorological Monographs, Vol. 26, No. 48, American Meteorological Society, 84 pp.

Sawford, B. L.: 1999, 'Rotation of Trajectories in Lagrangian Stochastic Models of Turbulent Dispersion', Boundary-Layer Meteorol. 93, 411-424.

Siqueira, M. and Katul, G. G.: 2002, 'Estimating Heat Sources and Fluxes in Thermally Stratified Canopy Flows Using Higher-Order Closure Models', Boundary-Layer Meteorol. 103, 125-142. 
Siqueira, M., Lai, C. T., and Katul, G.: 2000, 'Estimating Scalar Sources, Sinks, and Fluxes in a Forest Canopy Using Lagrangian, Eulerian, and Hybrid Inverse Models', J. Geophys. Res. 105, 29475-29488.

Taylor, G. I.: 1921, 'Diffusion by Continuous Movements', Proc. Lond. Math. Soc. Ser. 2, 20, 196221

Thomson, D. J.: 1987, 'Criteria for the Selection of Stochastic Models of Particle Trajectories in Turbulent Flows', J. Fluid Mech. 180, 529-556.

Warland, J. S. and Thurtell G. W.: 2000, 'A Lagrangian Solution to the Relationship between a Distributed Source and Concentration Profile', Boundary-Layer Meteorol. 96, 453-471.

Wilson, J. D. and Flesch, T. K.: 1997, 'Trajectory Curvature as a Selection Criterion for Valid Lagrangian Stochastic Models', Boundary-Layer Meteorol. 84, 411-426.

Wilson, J. D. and Sawford, B. L.: 1996, 'Review of Lagrangian Stochastic Models for Trajectories in the Turbulent Atmosphere', Boundary-Layer Meteorol. 78, 191-210.

Wilson N. R. and Shaw, R. H.: 1977, 'A Higher Order Closure Model for Canopy Flow', J. Appl. Meteorol. 16, 1198-1205. 